\title{
Reservoir operation using El Niño forecasts-case study of Daule Peripa and Baba, Ecuador
}

Gelati, Emiliano; Madsen, Henrik; Rosbjerg, Dan

Published in:

Hydrological Sciences Journal

Link to article, DOI:

10.1080/02626667.2013.831978

Publication date:

2014

Document Version

Publisher's PDF, also known as Version of record

Link back to DTU Orbit

Citation (APA):

Gelati, E., Madsen, H., \& Rosbjerg, D. (2014). Reservoir operation using El Niño forecasts-case study of Daule Peripa and Baba, Ecuador. Hydrological Sciences Journal, 59(8), 1559-1581.

https://doi.org/10.1080/02626667.2013.831978

\section{General rights}

Copyright and moral rights for the publications made accessible in the public portal are retained by the authors and/or other copyright owners and it is a condition of accessing publications that users recognise and abide by the legal requirements associated with these rights.

- Users may download and print one copy of any publication from the public portal for the purpose of private study or research.

- You may not further distribute the material or use it for any profit-making activity or commercial gain

- You may freely distribute the URL identifying the publication in the public portal

If you believe that this document breaches copyright please contact us providing details, and we will remove access to the work immediately and investigate your claim. 
This article was downloaded by: [DTU Library]

On: 26 November 2014, At: 03:40

Publisher: Taylor \& Francis

Informa Ltd Registered in England and Wales Registered Number: 1072954 Registered office: Mortimer House, 37-41 Mortimer Street, London W1T 3J H, UK

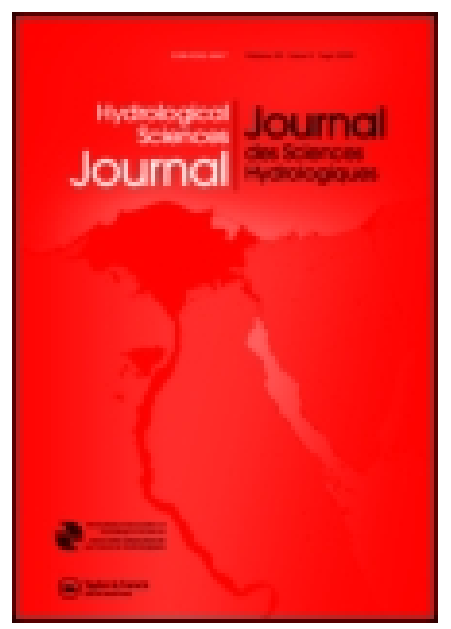

\title{
Hydrological Sciences J ournal
}

Publication details, including instructions for authors and subscription information:

http:// www. tandfonline.com/loi/thsj 20

\section{Reservoir operation using El Niño forecasts-case study of Daule Peripa and Baba, Ecuador}

\author{
E. Gelati ${ }^{a}$, H. Madsen ${ }^{b} \&$ D. Rosbjerg ${ }^{a}$ \\ ${ }^{a}$ Department of Environmental Engineering, Technical University of Denmark, Kongens \\ Lyngby, Denmark \\ ${ }^{\mathrm{b}}$ Water Resources Department, DHI, Hørsholm, Denmark \\ Accepted author version posted online: 08 Aug 2013. Published online: 30 J un 2014.
}

To cite this article: E. Gelati, H. Madsen \& D. Rosbjerg (2014) Reservoir operation using El Niño forecasts-case study of Daule Peripa and Baba, Ecuador, Hydrological Sciences J ournal, 59:8, 1559-1581, DOI: 10.1080/ 02626667.2013.831978

To link to this article: http:// dx. doi.org/ 10.1080/02626667.2013.831978

\section{PLEASE SCROLL DOWN FOR ARTICLE}

Taylor \& Francis makes every effort to ensure the accuracy of all the information (the "Content") contained in the publications on our platform. However, Taylor \& Francis, our agents, and our licensors make no representations or warranties whatsoever as to the accuracy, completeness, or suitability for any purpose of the Content. Any opinions and views expressed in this publication are the opinions and views of the authors, and are not the views of or endorsed by Taylor \& Francis. The accuracy of the Content should not be relied upon and should be independently verified with primary sources of information. Taylor and Francis shall not be liable for any losses, actions, claims, proceedings, demands, costs, expenses, damages, and other liabilities whatsoever or howsoever caused arising directly or indirectly in connection with, in relation to or arising out of the use of the Content.

This article may be used for research, teaching, and private study purposes. Any substantial or systematic reproduction, redistribution, reselling, loan, sub-licensing, systematic supply, or distribution in any form to anyone is expressly forbidden. Terms \& Conditions of access and use can be found at http:// www.tandfonline.com/page/terms-and-conditions 


\title{
Reservoir operation using El Niño forecasts-case study of Daule Peripa and Baba, Ecuador
}

\author{
E. Gelati ${ }^{1}$, H. Madsen ${ }^{2}$ and D. Rosbjerg ${ }^{1}$ \\ ${ }^{1}$ Department of Environmental Engineering, Technical University of Denmark, Kongens Lyngby, Denmark \\ emiliano.gelati@meteo.fr \\ Present address: $C N R M / G M M E / V E G E O$, Météo, France, Toulouse, France \\ ${ }^{2}$ Water Resources Department, DHI, Hørsholm, Denmark
}

Received 22 June 2012; accepted 9 July 2013; open for discussion until 1 February 2015

Editor D. Koutsoyiannis; Associate editor I. Nalbantis

Citation Gelati, E., Madsen, H., and Rosbjerg, D., 2014. Reservoir operation using El Niño forecasts—case study of Daule Peripa and Baba, Ecuador. Hydrological Sciences Journal, 59 (8), 1559-1581. http://dx.doi.org/10.1080/02626667.2013.831978

\begin{abstract}
Reservoir operation is studied for the Daule Peripa and Baba system in Ecuador, where El Niño events cause anomalously heavy precipitation. Reservoir inflow is modelled by a Markov-switching model using El Niño-Southern Oscillation (ENSO) indices as input. Inflow is forecast using 9-month lead time ENSO forecasts. Monthly reservoir releases are optimized with a genetic algorithm, maximizing hydropower production during the forecast period and minimizing deviations from storage targets. The method is applied to the existing Daule Peripa Reservoir and to a planned system including the Baba Reservoir. Optimized operation is compared to historical management of Daule Peripa. Hypothetical management scenarios are used as the benchmark for the planned system, for which no operation policy is known. Upper bounds for operational performance are found via dynamic programming by assuming perfect knowledge of future inflow. The results highlight the advantages of combining inflow forecasts and storage targets in reservoir operation.
\end{abstract}

Key words reservoir operation; optimization; inflow forecast; genetic algorithm; El Niño; Ecuador

\section{Gestion de réservoir utilisant des prévisions d'El Niño-étude de cas de Daule Peripa et de Baba, Equateur \\ Résumé On a étudié la gestion d'un réservoir pour le système de Daule Peripa et de Baba en Equateur, où les} événements El Niño causent des précipitations anormalement importantes. Les apports au réservoir ont été modélisés par un modèle à changement de régime markovien dont l'indice ENSO constitue l'entrée. Les prévisions d'apports utilisent les prévisions 9 mois à l'avance de l'indice ENSO. Les lâchures mensuelles du réservoir ont été optimisées grâce à un algorithme génétique, en maximisant la production hydroélectrique au cours de la période de prévision et en minimisant les écarts aux consignes de remplissage. La méthode a été appliquée au réservoir existant de Daule Peripa et à un système projeté comprenant le réservoir de Baba. La gestion optimisée a été comparée à l'historique de la gestion de Daule Peripa. Des scénarios de gestion hypothétiques ont été utilisés comme références pour le système projeté, pour lequel aucune politique de gestion n'est connue. Les limites supérieures de la performance opérationnelle ont été déterminées par programmation dynamique en supposant une connaissance parfaite des apports futurs. Les résultats mettent en évidence l'avantage pour la gestion des réservoirs de combiner les prévisions d'apports et les consignes de remplissage.

Mots clefs gestion de réservoir ; optimisation ; prévisions d'apports ; algorithme génétique ; El Niño ; Equateur

\section{INTRODUCTION}

Most current reservoir operation policies are based on heuristic rules or subjective judgements of the operators. As a consequence, many large reservoir projects are not completely achieving the objectives established during the planning phase (WCD 2000). Moreover, many existing policies fail to properly analyse multifacility systems, as the adoption of integrated operational strategies would result in dramatic increases in the number of alternative decisions (Labadie 2004). 
Therefore, the development of systematic and practical approaches to derive optimal operation policies for reservoir systems has been extensively studied during the last decades (Yeh 1985, Simonovic 1992, Wurbs 1993, Labadie 2004). However, a persistent gap between theoretical advances and real implementations has been observed. Among the reasons for such a gap, Labadie (2004) mentioned the mathematical complexity and the difficulty in accounting for risk and uncertainty of many optimization models.

The inclusion of input uncertainty is compulsory if we want to enhance the operational efficiency by using inflow forecasts. Input uncertainty in reservoir system optimization has been considered by either explicit stochastic optimization (ESO) or implicit stochastic optimization (ISO) methods (Tickle and Goulter 1994). ESO works on probabilistic descriptions of the stochastic variables, thus dealing directly with the associated uncertainty, while ISO includes input uncertainty indirectly by optimizing over a number of equally likely historical or synthetic time series. The main drawback of ISO is that, in principle, the obtained operation policies are valid only for the used input time series. However, in comparison with ESO, ISO allows a more complete representation of the problem (Karamouz and Houck 1987, Rani and Moreira 2010). Moreover, in multi-reservoir applications, ESO yields higher computational costs than ISO (Roefs and Bodin 1970).

Traditional optimization algorithms that can be applied in both ISO and ESO versions, such as linear programming (LP) and dynamic programming (DP), are reviewed by Yeh (1985) and Labadie (2004). These methods are affected by important drawbacks: LP requires the system description to be linear, while many processes, e.g. hydropower generation, cannot be acceptably approximated by linear functions; the applicability of DP is limited by the computational costs growing exponentially with the number of system state variables. Thus, in many cases, these methods are only applicable for simplified reservoir systems (Chen 2003).

Among ISO methods, the simulation-optimization (SO) approach combines simulation models with heuristic search procedures such as genetic algorithms (GAs). The main drawback of SO is the high number of simulations that need to be performed. However, SO has gained popularity due to the continuous advancement of computational power, its ease of implementation and its applicability to nonlinear and non-convex optimization problems. GAs, as well as other heuristics, cannot guarantee the attainment of global optima. However, they can produce satisfactory solutions to problems where traditional gradient-based algorithmic methods would fail or lead to local optima. Several studies have proved the efficacy of the SO approach: Oliveira and Loucks (1997) used GAs to perform multi-objective optimization of complex reservoir systems with constraints on releases and hydropower production; Sharif and Wardlaw (2000) used GAs to optimize a multi-reservoir system in the Brantas basin in Indonesia; Chen (2003) applied a GA in combination with a simulation model to optimize the rule curves of a major reservoir system in Taiwan and Ngo et al. (2007) used the shuffled complex evolution algorithm to optimize the Hoa Binh Reservoir in Vietnam. Several stochastic optimizations of water resources systems were carried out by coupling GAs with sampling objective functions, which are computed by averaging over multiple noisy evaluations, in order to account for input or parameter uncertainty (Smalley et al. 2000, Gopalakrishnan et al. 2001, Kapelan et al. 2006, Wu et al. 2006).

Several authors acknowledged that the use of forecasts in reservoir operation yields better results than reactive control, which does not consider forecasts (Labadie et al. 1981, Mishalani and Palmer 1988, Georgakakos 1989). In several studies, short-term reservoir operation was implemented using inflow forecasts without considering any long-term information (Simonovic and Burn 1989, Mujumdar and Ramesh 1997, Mujumdar and Teegavarapu 1998). However, as forecast accuracy generally becomes poorer as lead times grow, short-term reservoir operation may be improved by integrating information from optimized long-term operation (Yeh 1985, Celeste et al. 2008). Moreover, using information about the long-term optimum may compensate the intrinsic short-sightedness of short-term operation strategies.

This study considers the operation of the Daule Peripa and Baba reservoirs (Ecuador). We follow the SO approach and use a GA to optimize hydropower production at the monthly time scale. Although hydropower systems are typically operated at shorter time scales, data availability forced the development of methodologies that use monthly time intervals. Thus, our purpose is to show the potential for operational improvement by using monthly inflow forecasts, while acknowledging that operational system simulation and optimization tools should be defined at shorter time scales. At each time interval, reservoir releases are decided by exploiting inflow forecast scenarios and monthly storage targets. Inflow 
forecasts are generated for lead times of up to 9 months by a stochastic model using forecasts of ENSO as input. Monthly storage targets are estimated by applying DP to historical inflow time series. By combining inflow forecasts and storage targets, the presented method integrates short- and long-term information in reservoir system optimization. While forecasts provide information for the short-term time horizon (9 months), storage targets guarantee the long-term sustainability of reservoir operation beyond such a horizon.

The Daule Peripa and Baba reservoirs are located in western Ecuador, where El Niño is associated with anomalously heavy precipitation, which is caused by positive sea surface temperature (SST) anomalies in the equatorial Pacific Ocean (Vuille et al. 2000). To account for the influence of ENSO, we extended the stochastic model by Gelati et al. (2010b) to generate multivariate inflow forecast scenarios. The model is a mixture of autoregressive models with exogenous input (ARX) using ENSO indices as regressors. The shifts between ARX spells are described by a first-order Markov chain, whose transition probabilities are functions of ENSO indices. The applied model is a Markov-switching model (Cappè et al. 2005) derived from the work of Hamilton (1989), who modelled the gross domestic product with an autoregressive model conditioning the parameters on a Markov chain that shifted between economic growth and recession phases. This approach was extended using a non-homogeneous Markov chain (i.e. with time-variant transition probabilities), which was previously applied in non-homogeneous hidden Markov models for downscaling large-scale atmospheric variables to precipitation (Hughes and Guttorp 1994, Hughes et al. 1999, Bellone et al. 2000, Robertson et al. 2004, Gelati et al. 2010a). Akintuğ and Rasmussen (2005) used Markov-switching models to generate annual streamflow time series, conditioning the probability distribution of runoff on a hidden climate state following a Markov chain. Our modelling approach attempts to account for the climatic influence on multivariate inflow and for the non-linearities in inflow autocorrelation and cross-correlation with climatic variables.

With respect to the work by Gelati et al. (2011), which used similar methodologies for the same case study area, this study contributes with the following innovative elements:

- the planned Baba Reservoir is included in the study;

- the stochastic inflow model is extended to multivariate time series;
- reservoir releases are optimized with a singleobjective search algorithm by giving highest priority to the satisfaction of downstream water demands, instead of the multi-objective approach used by Gelati et al. (2011);

- the objective function that measures hydropower production is modified by introducing a penalty term accounting for monthly storage targets.

In Section 6.2, we compare the results obtained by the new methodologies with those presented by Gelati et al. (2011) for the Daule Peripa Reservoir. Parts of the work presented here are briefly summarized in the PhD thesis of Gelati (2010).

This paper has the following structure: in Section 2, we describe the application data and the influence of ENSO on inflow; in Section 3, we define the stochastic model for multivariate inflow, describing parameter estimation and inflow forecasting; in Section 4, we describe the Daule Peripa and Baba reservoir system, for which we define a simulation model; in Section 5, we formulate the reservoir system operation procedure; in Section 6, we present and discuss the results; and in Section 7, we summarize the achievements of this study. The expectationmaximization algorithm, which is used for parameter estimation of the stochastic inflow model, is given in Appendix A, and in Appendix B we formulate the optimization problem that is solved via DP.

\section{INFLOW AND ENSO DATA}

The ENSO indices, which we use to forecast inflow, are derived from SST measured on several areas of the equatorial Pacific Ocean: Niño $1+2\left(0^{\circ}-10^{\circ} \mathrm{S}, 90^{\circ}-\right.$ $\left.80^{\circ} \mathrm{W}\right)$; Niño $3\left(5^{\circ} \mathrm{N}-5^{\circ} \mathrm{S}, 150^{\circ}-90^{\circ} \mathrm{W}\right)$; Niño $3+4\left(5^{\circ}\right.$ $\left.\mathrm{N}-5^{\circ} \mathrm{S}, 170^{\circ}-120^{\circ} \mathrm{W}\right)$ and Niño $4\left(5^{\circ} \mathrm{N}-5^{\circ} \mathrm{S}, 160^{\circ} \mathrm{E}-\right.$ $\left.150^{\circ} \mathrm{W}\right)$. Figure 1 shows the location of the water resources system and the regions where SSTs are measured. We also considered the Trans-Niño Index (TNI), which is the difference between Niño $1+2$ and Niño 4 SST anomalies (Trenberth and Stepaniak 2001). The SST data were obtained for 1950-2008 from the NOAA Climate Prediction Center (Camp Springs, MD, USA), which also issues monthly forecasts of ENSO-related SST with a 9-month lead time.

Monthly inflow time series are available from 1950 to 2008 for Daule Peripa and from 1950 to 2004 for Baba. Daule Peripa receives a larger average inflow $\left(176 \mathrm{~m}^{3} / \mathrm{s}\right)$ than Baba $\left(107 \mathrm{~m}^{3} / \mathrm{s}\right)$. This difference is primarily due to different inflows between February and May, which are the wettest months for 


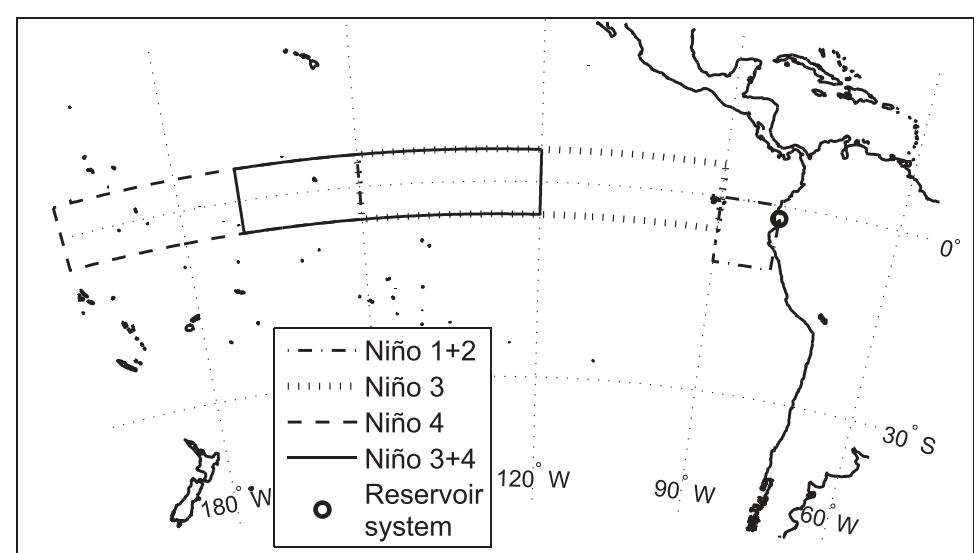

Fig. 1 Location of the Daule Peripa and Baba reservoir system and areas of the Pacific Ocean where sea surface temperatures (SSTs) related to the El Niño-Southern Oscillation are measured (Gelati et al. 2010b).

both catchments according to the historical records. According to average monthly inflow values (Fig. 2), February-May inflow constitutes $76 \%$ and $66 \%$ of total annual inflow for Daule Peripa and Baba, respectively.

Annual anomalies of inflow and Niño $1+2$ SST (Fig. 3) give an overview of how ENSO indices correlate with the Daule Peripa and Baba inflow. We used annual anomalies for this preliminary analysis, to disregard the impact of seasonality and to provide visually interpretable results. Niño $1+2 \mathrm{SST}$ was chosen for this comparison as it showed the largest correlation with inflow among the selected ENSO indices. The anomalies were obtained by aggregating monthly data into annual time series, and by standardizing with respect to sample means and standard deviations. The annual inflow anomalies of Daule Peripa and Baba are well correlated with each other (the correlation coefficient is 0.86). The correlation coefficients between annual anomalies of Niño $1+2$ SST and of Daule Peripa and Baba inflow are 0.68 and 0.72 , respectively. While Daule Peripa and Baba inflow anomalies correlate well with positive Niño $1+2$ SST anomalies (coefficients are 0.80 and 0.78 ), their correlation coefficients with negative anomalies are slightly negative $(-0.19$ and $-0.08)$. This suggests that El Niño is well correlated with positive inflow anomalies, while La Niña does not have a significant impact on inflow, as also found by Gelati et al. (2010b) for Daule Peripa. El Niño and

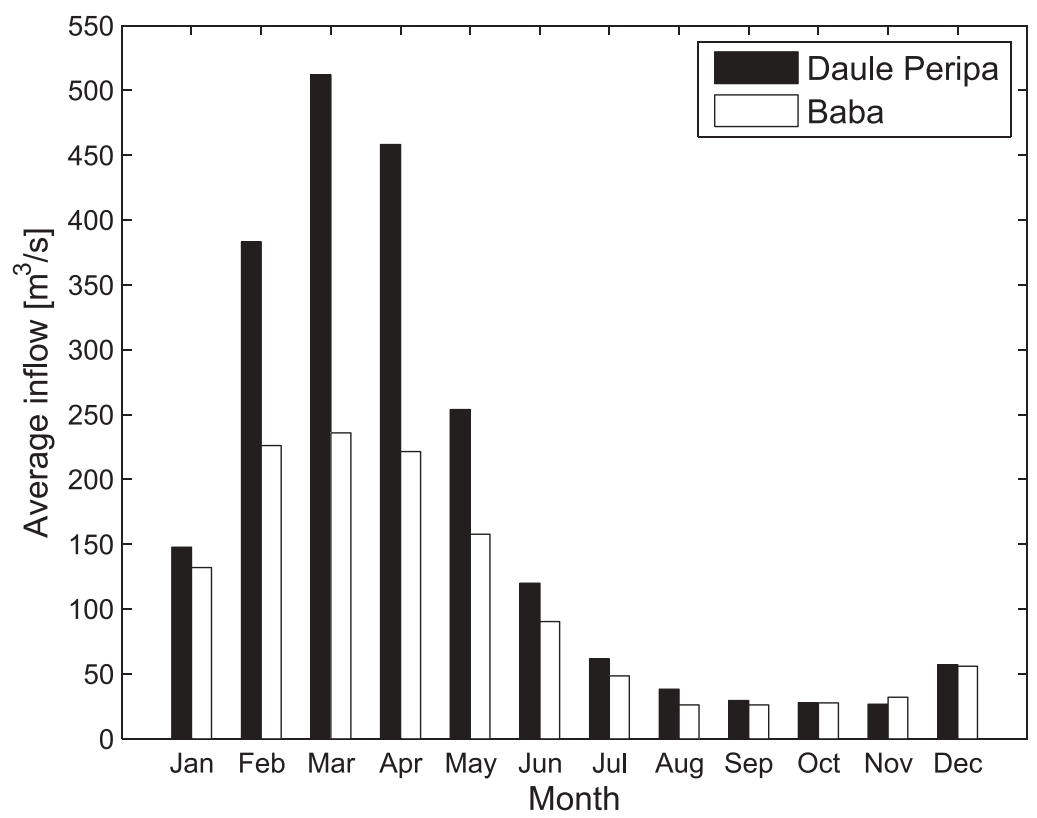

Fig. 2 Average monthly inflow of the Daule Peripa and Baba reservoirs (1950-2004). 


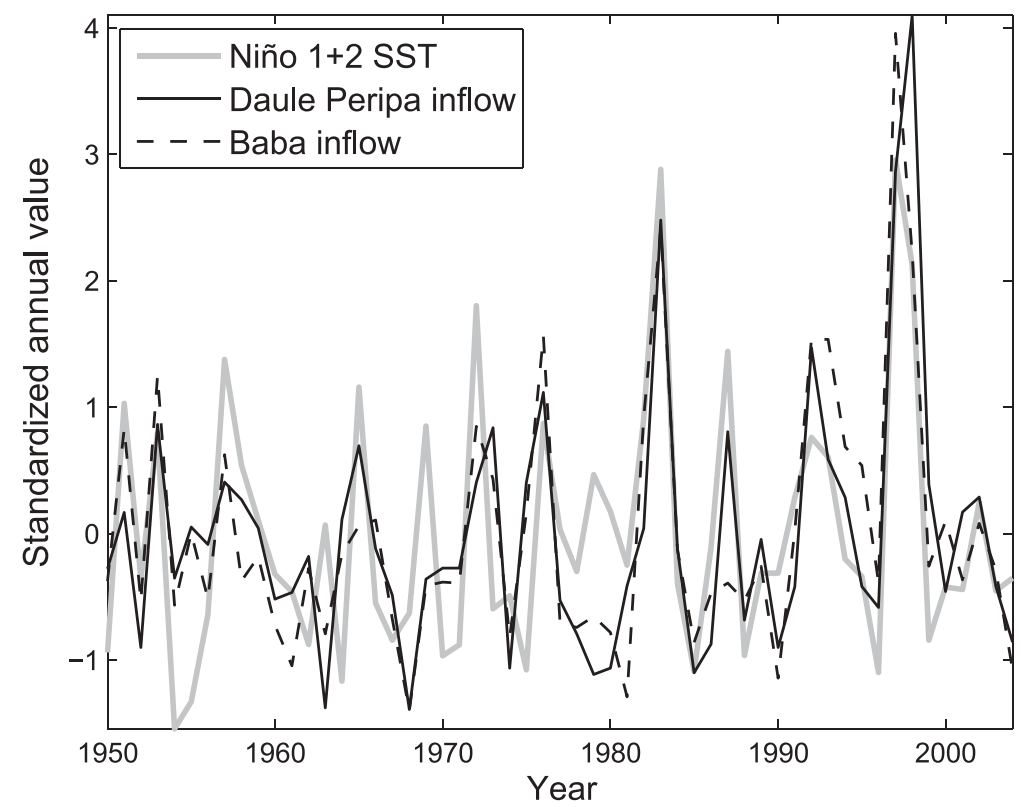

Fig. 3 Standardized annual time series of inflow and El Niño $1+2$ sea surface temperature (SST).

La Niña phases of ENSO are identified by positive and negative SST anomalies in the equatorial Pacific Ocean, respectively (Trenberth 1997).

Monthly time series were standardized to describe inflow with a non-seasonal stochastic model. As illustrated in equations (1) and (2), ENSO indices were de-seasonalized with respect to monthly means and standard deviations, while inflow data were log-transformed and then de-seasonalized. Log-transformation was applied because of the significant positive skewness of monthly inflow to treat model noise as a Gaussian process. Indeed skewness coefficients score up to 7.0 for Daule Peripa and 5.3 for Baba. We found that inflow values for each month are well described by two-parameter log-normal distributions. Although a three-parameter formulation would have offered more flexibility for modelling the skews, we chose a two-parameter approach to limit the dimensions of the transformations.

$$
\begin{aligned}
& c_{t}(i)=\frac{l_{t}(i)-E_{l(i)}(m(t))}{D_{l(i)}(m(t))} \\
& a_{t}(j)=\frac{\log \left[q_{t}(j)\right]-E_{\log [q(i)]}(m(t))}{D_{\log [q(j)]}(m(t))}
\end{aligned}
$$

where $l_{t}(i)$ and $q_{t}(j)$ are the $i$ th ENSO index and the $j$ th inflow value at monthly time interval $t ; c_{t}(i)$ and $a_{t}(j)$ are the corresponding anomalies; $m(t)$ returns the calendar month corresponding to time interval $t$ and $E_{z}(n)$ and
$D_{z}(n)$ are the sample mean and standard deviation of the generic variable $z$ for calendar month $n$.

\section{A MULTIVARIATE INFLOW MODEL USING ENSO INFORMATION}

To describe multiple reservoir inflow accounting for the influence of ENSO, we define a multivariate Markov-switching autoregressive model with exogenous input. The developed method extends the model presented by Gelati et al. (2010b), which applies to univariate inflow.

\subsection{Model definition}

We define a model to mimic ENSO-induced shifts between inflow regimes and correlate ENSO indices to inflow. We assume that the multivariate inflow anomaly process is conditioned on an unobserved climate state process. The climate state at time interval $t$ is represented by the discrete stochastic variable $s_{t}$ that can take on values $1, \ldots, S$. The climate state is unobserved (or hidden) and follows a first-order Markov chain, where transition probabilities are time variant and depend on the current ENSO indices. Using the parameterization introduced by Hughes and Guttorp (1994) for non-homogeneous hidden Markov models, state transition probabilities are: 


$$
\begin{aligned}
& \operatorname{Pr}\left\{s_{t}=i \mid s_{t-1}=j, \boldsymbol{c}_{t}, \boldsymbol{\theta}\right\} \\
& \propto p_{i j} \exp \left[-\frac{1}{2}\left(\boldsymbol{c}_{t}-\boldsymbol{\mu}_{j}\right)^{\prime} \boldsymbol{V}\left(\boldsymbol{c}_{t}-\boldsymbol{\mu}_{j}\right)\right]
\end{aligned}
$$

where $\boldsymbol{c}_{t}$ is the vector of ENSO indices at time interval $t ; \boldsymbol{\theta}$ is the set of model parameters; $p_{i j}$ is the stationary component of the transition probability from state $i$ to $j$; $\boldsymbol{V}$ is a scale matrix; $\boldsymbol{\mu}_{i}$ is the value of $\boldsymbol{c}_{t}$ that maximizes the probability of shifting to state $i$; and ' is the vector transpose operator. To guarantee parameter identifiability, $p_{i j}$ have to fulfil the constraints $\sum_{j=1}^{S} p_{i j}=1$, for $i=1, \ldots, S$. To reduce the number of free parameters, $\boldsymbol{V}$ is set equal to the inverse of the covariance matrix of $\boldsymbol{c}_{t}$ (Hughes and Guttorp 1994, Hughes et al. 1999, Bellone et al. 2000).

The climate state is defined as a stochastic variable that drives the inflow anomaly processes. We assume that multiple inflow anomalies are described by a multivariate ARX, whose parameters are conditioned on the current climate state. Let $\boldsymbol{a}_{t}$ be the vector of inflow anomalies at time interval $t$. Assuming the multivariate ARX noise to be a Gaussian stationary and uncorrelated process, the conditional probability density function of $\boldsymbol{a}_{t}$ is:

$$
\begin{gathered}
f\left(\boldsymbol{a}_{t} \mid s_{t}=i, \boldsymbol{a}_{t-1}, \boldsymbol{c}_{t}, \boldsymbol{\theta}\right)=\frac{1}{\sqrt{(2 \pi)^{K} \operatorname{det}\left(\boldsymbol{\Omega}_{i}\right)}} \\
\exp \left[\frac{1}{2}\left(\boldsymbol{a}_{t}-\boldsymbol{\delta}_{i}-\operatorname{diag}\left(\boldsymbol{a}_{t-1}\right) \lambda_{i}-\boldsymbol{\Gamma}_{i} \boldsymbol{c}_{t}\right)^{\prime}\right. \\
\left.\boldsymbol{\Omega}_{i}^{-1}\left(\boldsymbol{a}_{t}-\boldsymbol{\delta}_{i}-\operatorname{diag}\left(\boldsymbol{a}_{t-1}\right) \boldsymbol{\lambda}_{i}-\boldsymbol{\Gamma}_{i} \boldsymbol{c}_{t}\right)\right]
\end{gathered}
$$

where $\boldsymbol{a}_{0}$ is defined to be a vector of zeroes, $K$ is the length of $\boldsymbol{a}_{t}, \operatorname{det}(\cdot)$ is the matrix determinant operator, $\operatorname{diag}\left(\boldsymbol{a}_{t-1}\right)$ is a diagonal matrix constituted by the elements of $\boldsymbol{a}_{t-1}$ and $\boldsymbol{\delta}_{i}, \lambda_{i}, \boldsymbol{\Gamma}_{i}$ and $\boldsymbol{\Omega}_{i}$ are the multivariate ARX parameters for state $i$. In particular, $\boldsymbol{\delta}_{\boldsymbol{i}}$ and $\lambda_{i}$ are the $K \times 1$ vectors of intercept and autoregressive parameters, respectively; $\boldsymbol{\Gamma}_{i}$ is the $K \times N$ matrix of exogenous correlation parameters, where $N$ is the length of $\boldsymbol{c}_{t}$ and $\boldsymbol{\Omega}_{i}$ is the $K \times K$ covariance matrix of the multivariate residual process, conditioned on $s_{t}=i$ :

$$
\begin{aligned}
\Omega_{i} & =\operatorname{cov}\left(\boldsymbol{a}_{t}-\boldsymbol{\delta}_{i}-\operatorname{diag}\left(\boldsymbol{a}_{t-1}\right) \boldsymbol{\lambda}_{i}-\boldsymbol{\Gamma}_{i} \boldsymbol{c}_{t}\right) \\
& =\boldsymbol{\Xi}_{i} \boldsymbol{\Psi}_{i} \boldsymbol{\Xi}^{\prime}{ }_{i}
\end{aligned}
$$

where the columns of $\boldsymbol{\Xi}_{i}$ are the eigenvectors of $\boldsymbol{\Omega}_{i}$; and the elements of the diagonal matrix $\boldsymbol{\Psi}_{i}$ are the eigenvalues of $\boldsymbol{\Omega}_{i}$.

Conditional on $s_{t}=i$, the multivariate inflow anomaly process is parameterized as:

$$
\boldsymbol{a}_{t}=\boldsymbol{\delta}_{i}+\operatorname{diag}\left(\boldsymbol{a}_{t-1}\right) \boldsymbol{\lambda}_{i}+\boldsymbol{\Gamma}_{i} \boldsymbol{c}_{t}+\boldsymbol{\Xi}_{i} \boldsymbol{\Psi}_{i}^{\frac{1}{2}} \boldsymbol{\varepsilon}_{t}
$$

where $\boldsymbol{\varepsilon}_{t}$ is a vector of $K$-independent white noise standard Gaussian processes.

\subsection{Parameter estimation}

The free parameter set is $\boldsymbol{\theta}=\left[p_{i j}, \boldsymbol{\mu}_{i}, \boldsymbol{\delta}_{i}, \boldsymbol{\lambda}_{i}, \boldsymbol{\Gamma}_{i}, \boldsymbol{\Omega}_{i}\right]$ for $i=1, \ldots, S$ and $j=1, \ldots, S-1$. To estimate $\theta$, we apply the expectation-maximization (EM) algorithm, which is an iterative maximum likelihood calibration method. The EM algorithm treats the hidden climate states as missing observations and requires parameter estimates to be initialized. The EM algorithm was developed for hidden Markov models (Baum et al. 1970, Dempster et al. 1977) and later applied to nonhomogeneous hidden Markov models by Hughes et al. (1999). The EM algorithm for the stochastic inflow model is described in Appendix A.

\subsection{Forecast}

In this application, the stochastic inflow model is used to generate inflow forecasts via simulation given past observations and ENSO forecasts. Let us introduce the following notation rule: if $z_{t}$ is a generic vector at time interval $t$, then $\tilde{\boldsymbol{z}}_{t}$ is its forecast and $\boldsymbol{z}_{T_{1}: T_{2}}$ and $\tilde{\boldsymbol{z}}_{T_{1}: T_{2}}$ are the time series of, respectively, $\boldsymbol{z}_{t}$ and $\tilde{\boldsymbol{z}}_{t}$ between time intervals $T_{1}$ and $T_{2}$. To generate an inflow forecast time series $\tilde{\boldsymbol{q}}_{T_{1}: T_{2}}$ conditioned on past observations $\boldsymbol{a}_{1: T_{1}-1}$ and $\boldsymbol{c}_{1: T_{1}-1}$, on ENSO indices forecasts $\tilde{\boldsymbol{c}}_{T_{1}: T_{2}}$, and on model parameters $\boldsymbol{\theta}$, four steps have to be performed:

(i) The probability mass function of $s_{T_{1}}$ is estimated as:

$$
\begin{aligned}
& \operatorname{Pr}\left\{s_{T_{1}}=i \mid \boldsymbol{a}_{1: T_{1}-1}, \boldsymbol{c}_{1: T_{1}-1}, \tilde{\boldsymbol{c}}_{T_{1}}, \boldsymbol{\theta}\right\} \\
& =\sum_{j=1}^{S} \alpha_{T_{1}-1}(j) \operatorname{Pr}\left\{s_{T_{1}}=i \mid s_{T_{1}-1}=j, \tilde{\boldsymbol{c}}_{T_{1}}, \boldsymbol{\theta}\right\}
\end{aligned}
$$

where $\alpha_{t}(i)$ is the probability of state $i$ to occur at time interval $t$, given the observations until $t$ and model parameters: 
$\alpha_{t}(i)=\operatorname{Pr}\left\{s_{t}=i \mid \boldsymbol{a}_{1: t}, \boldsymbol{c}_{1: t}, \boldsymbol{\theta}\right\}$

The values taken by the variable $\alpha_{t}(i)$ are computed by forward recursion, which is a part of the Baum-Welch algorithm (Baum et al. 1970, Rabiner 1989). A description of the Baum-Welch algorithm for non-homogeneous hidden Markov models is given in Gelati et al. (2010a) and is applicable to the presented Markov-switching model.

(ii) A climate state time series $\tilde{\boldsymbol{s}}_{T_{1}: T_{2}}$ is generated using the probabilities computed with equations (7) and (3), where $\boldsymbol{c}_{T_{1}: T_{2}}$ are replaced by the forecasts $\tilde{\boldsymbol{c}}_{T_{1}: T_{2}}$.

(iii) The inflow anomaly forecasts $\tilde{\boldsymbol{a}}_{T_{1}: T_{2}}$ are recursively generated with equation (6): observations are used for $\boldsymbol{a}_{T_{1}-1}$, while $\boldsymbol{a}_{t}$ is replaced by $\tilde{\boldsymbol{a}}_{t}$, which is the value forecast by the previous recursion, for $t=T_{1}, \ldots, T_{2}$.

(iv) The inflow forecast time series $\tilde{\boldsymbol{q}}_{T_{1}: T_{2}}$ is obtained from $\tilde{\boldsymbol{a}}_{T_{1}: T_{2}}$ by inverting equation (2).

For the purpose of model testing, we used observed ENSO data to generate synthetic inflow. Thus, we assumed $\tilde{\boldsymbol{c}}_{T_{1}: T_{2}}$ to be equal to $\boldsymbol{c}_{T_{1}: T_{2}}$. In a real-life application, ENSO forecast data would be used to forecast inflow. Although ENSO forecast accuracy would affect the quality of operational inflow forecasts, evaluating the predictive capabilities of currently available ENSO forecasts is out of the scope of this study. Indeed, the presented methodology is not directly applicable within an operational context.

\section{THE WATER RESOURCES SYSTEM}

The main elements of the water resources system are the Daule Peripa and Baba reservoirs, located in western Ecuador (Fig. 1). The Daule Peripa Reservoir, which was completed in 1987, receives its inflow from the Daule and Peripa rivers and serves a hydropower plant and downstream water users. The Baba Reservoir, currently under construction, will receive its inflow from the Baba River and is planned to supply downstream users and a water transfer to Daule Peripa Reservoir. The water transferred from Baba to Daule Peripa will be turbinated by a hydropower plant. For both reservoirs, the downstream water demands are aggregates of household water supply, irrigation and environmental flows, and their satisfaction is given the highest priority.
Figure 4 schematizes the water resources system, distinguishing between existing and planned elements. In the remainder of the manuscript, we refer to the existing elements as the Daule Peripa Reservoir, and its downstream hydropower plant and water users, while the added elements are the Baba Reservoir, its downstream water users and the hydropower plant turbinating the water transferred from Baba to Daule Peripa.

Monthly time series of reservoir water level and hydropower are available from 2000 to 2008 for Daule Peripa, while no planned operation policy of Baba is known to the authors.

Table 1 summarizes the characteristics of the water resources system, obtained from DHI (Hørsholm, Denmark). The storage capacities of both reservoirs are smaller than the corresponding average annual inflow volumes. The volume ratio between average annual inflow and active storage is 1.6 for Daule Peripa and 27 for Baba. Thus, the potential for water management is significantly larger for Daule Peripa than for Baba. Although the relatively small storage of Baba has a limited impact on the flow regime at a monthly time scale, Baba Reservoir is included in this study as it is planned to contribute to hydropower production and to transfer water to Daule Peripa.

\subsection{Simulation model}

Based on the available data, we made the following assumptions to define a simulation model for the water resources system:

- Reservoir inflows are net values; thus, precipitation and evaporation at the reservoir surface as well as storage gains and losses due to filtration are not explicitly included in the water balance.

- Simulation time intervals are 1 month long.

- During each time interval, all water flows are constant.

Then, the water balance equations of the reservoirs for time interval $t$ are:

$$
v^{e}(x)=v^{e}\left(\tau_{t-1}\right)+\left(x-\tau_{t-1}\right)\left(q_{t}^{e}+r_{t}^{a}-r_{t}^{e}-w_{t}^{e}\right)
$$

$$
v^{a}(x)=v^{a}\left(\tau_{t-1}\right)+\left(x-\tau_{t-1}\right)\left(q_{t}^{a}-r_{t}^{a}-w_{t}^{a}\right)
$$




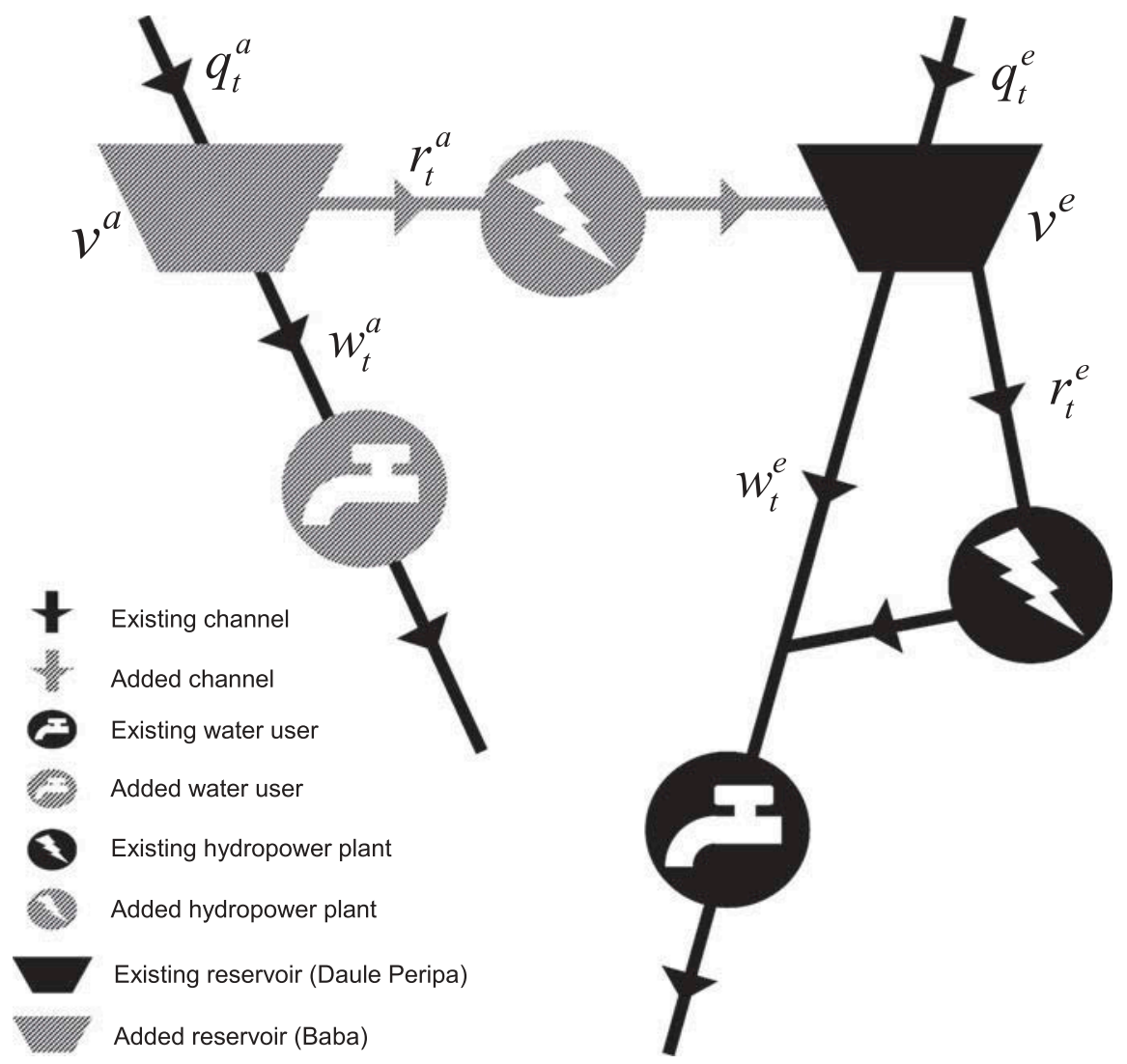

Fig. 4 Scheme of the water resources system: existing and added elements are represented together with the terms of the water balance equations (9) and (10).

Table 1 Summary of the water resources system characteristics.

\begin{tabular}{|c|c|c|c|c|c|c|c|}
\hline \multirow[t]{2}{*}{ Element } & \multicolumn{3}{|l|}{ Reservoir } & \multicolumn{3}{|l|}{ Turbine } & \multirow{2}{*}{$\begin{array}{l}\text { Downstream } \\
\text { Water } \\
\text { demand } \\
\left(\mathrm{m}^{3} / \mathrm{s}\right)\end{array}$} \\
\hline & $\begin{array}{l}\text { Active } \\
\text { storage } \\
\left(10^{9} \mathrm{~m}^{3}\right)\end{array}$ & $\begin{array}{l}\text { Minimum } \\
\text { level (m) }\end{array}$ & $\begin{array}{l}\text { Maximum } \\
\text { level (m) }\end{array}$ & $\begin{array}{l}\text { Hydraulic } \\
\text { capacity } \\
\left(\mathrm{m}^{3} / \mathrm{s}\right)\end{array}$ & $\begin{array}{l}\text { Power } \\
\text { capacity } \\
(\mathrm{MW})\end{array}$ & $\begin{array}{l}\text { Average } \\
\text { efficiency (-) }\end{array}$ & \\
\hline Existing & 3.534 & 70 & 86 & 396 & 213 & 0.835 & 60 \\
\hline Added & 0.123 & 105 & 120 & 250 & 65 & 0.901 & 10 \\
\hline
\end{tabular}

Note: Existing and added elements refer to the Daule Peripa and Baba reservoirs, respectively.

where $\tau_{t-1}$ is the end time of time interval $t-1$; the superscript indices $e$ and $a$ indicate terms referring to existing and added system elements (Fig. 4); $v^{i}(x)$ are the storage volumes at time $x$, for $\tau_{t-1}<\times \leq \tau_{t}$ and $q_{t}^{i}$, $r_{t}^{i}$ and $w_{t}^{i}$ are average inflow, turbine flow and downstream release rates, respectively, during time interval $t$, for $i=a, e$.

Let $g_{t}$ be the average power generated by the hydropower plants during time interval $t$ :

$$
g_{t}=\phi \sum_{i=a, e} \varepsilon^{i} r_{t}^{i}\left(\bar{h}_{t}^{i}-k_{t}^{i}\right)
$$

where $\phi$ is the specific weight of water, $\varepsilon^{i}$ are the turbine efficiencies and $\bar{h}_{t}^{i}$ and $k_{t}^{i}$ are the average reservoir water levels and tailwater heights during time interval $t$, for $i=a, e$.

\section{RESERVOIR OPERATION USING INFLOW FORECASTS}

Reservoir operation is defined to exploit the monthly ENSO forecasts that are issued with a 9-month lead time. At the beginning of each monthly time interval 
$t$, system operation is decided according to the following steps:

(i) Based on the forecasts of ENSO indices $\tilde{\boldsymbol{c}}_{t: t+8}$, several 9-month-long inflow forecast scenarios are generated with the stochastic inflow model.

(ii) The decision variables are optimized for the forecast period using inflow forecasts as stochastic input to compute the objective function. The search of the optimal values for the decision variables is performed by a GA (Goldberg 1989, Holland 1992).

(iii) The system is operated during the first time interval $t$ according to the optimized decision variables.

(iv) The state of the system is updated at the end of time interval $t$.

(v) The procedure is iterated for time interval $t+1$.

In the remainder of this section, we describe the decision variables and the objective function that are used to optimize reservoir operation.

\subsection{Decision variables}

According to the water resources system model described in Section 4.1, system operation during time interval $t$ is defined by the monthly releases $x_{t}^{i}$ and $w_{t}{ }^{i}$ for $i=a, e$ (Fig. 4). If all releases had to be optimized for the 9-month forecast period, the number of decision variables would be 36 . Let $W^{i}$ be the water demands of the downstream users, $R^{i}$ the hydraulic capacities of the turbines and $V^{i}$ the active storage, for $i=a, e$ (Table 1). To limit the number of decision variables, we make the following assumptions about the reservoir system during a time interval $t$, for $\tau_{t-1}<\times \leq \tau_{t}$ :

(a) the Daule Peripa turbine release fulfils the downstream water demand unless the reservoir is emptied, i.e. $r_{t}^{e} \geq W^{e}$ if $v^{e}(x)>0$;

(b) the Daule Peripa non-turbinated release does not occur unless turbine capacity is reached and the reservoir is full, i.e. $w_{i}^{e}=0$ if $r_{t}^{e}<R^{e}$ or $v^{e}(x)<V^{e}$;

(c) the Baba downstream water demand is satisfied unless the reservoir is emptied, i.e. $w_{t}{ }^{a} \geq W^{a}$ if $v^{a}(x)>0$;

(d) water is turbinated and transferred from Baba to Daule Peripa if the Baba downstream water demand is satisfied, i.e. $r_{t}^{a}>0$ if $w_{t}^{a} \geq W^{a}$;

(e) the Baba non-turbinated release does not exceed the downstream water demand unless turbine capacity is reached and the reservoir is full, i.e. $w_{t}^{a}=W^{a}$ if $r_{t}^{a}<R^{a}$ or $v^{a}(x)<V^{a}$.

Assumptions (a), (c) and (d) derive from prioritizing the satisfaction of the water demands of the downstream users. Assumption (b) is motivated by the fact that the turbine release of Daule Peripa, $r_{t}^{e}$, is available to the existing downstream water user. Assumption (e) states that Baba downstream release may exceed downstream water demand if and only if the reservoir is full and the turbine release cannot be increased. Thus, the sole releases $\boldsymbol{r}_{t}$ determine the system operation during time interval $t$.

Let $\boldsymbol{\rho}_{t}=\left[\rho_{t}^{e}, \rho_{t}^{a}\right]$ be the turbine release fractions of Daule Peripa and Baba for time interval $t$ :

$$
\begin{aligned}
& r_{t}^{e}=W^{e}+\rho_{t}^{e}\left(R^{e}-W^{e}\right) \\
& r_{t}^{e}=\rho_{t}^{a} R^{a}
\end{aligned}
$$

where $0 \leq \rho_{t}^{i} \leq 1$ so that $r_{t}^{i} \leq R^{i}$, for $i=e$, $a$. The decision variables to be optimized at the beginning of time interval $t$ are then $\boldsymbol{\rho}_{t: t+8}=\left[\boldsymbol{\rho}_{t}, \ldots, \boldsymbol{\rho}_{t+8}\right]$. Thus, the number of decision variables is reduced to 9 multiplied by the number of reservoirs. Let $\hat{\boldsymbol{\rho}}_{t: t+8}$ be the optimized turbine release fractions obtained at the beginning of $t$, then only $\hat{\boldsymbol{\rho}}_{\boldsymbol{t}}$ are implemented during time interval $t$.

\subsection{Objective function}

The known purposes of the Daule Peripa and Baba reservoirs are hydropower production and meeting the demands of the downstream water users. The assumptions formulated in Section 5.1 simplify the optimization problem by prioritizing the satisfaction of downstream water demands during each time interval. Thus, reservoir system operation is determined by solving a single-objective optimization problem at the beginning of each time interval: at the beginning of time interval $t, \boldsymbol{\rho}_{t: t+8}$ are optimized by minimizing an objective function that measures the hydropower production performance.

The objective function is defined as a weighted sum of the expected root mean square hydropower deficit (RMSHD) from $t$ to $t+8$ and of a penalty term estimating the expected RMSHD beyond $t+8$ : 


$$
\begin{aligned}
& Y\left(\tilde{\boldsymbol{Q}}_{t: t+8}^{L}, \boldsymbol{\rho}_{t: t+8}\right) \\
& =(1-\omega) \sqrt{\frac{1}{9 L} \sum_{l=1}^{L} \sum_{d=t}^{t+8}\left(G-\tilde{g}_{d}^{(l)}\right)^{2}} \\
& +\omega \frac{1}{L} \sum_{l=1}^{L} F\left(m(t+8), \tilde{h}_{t+8}^{(l)}\right)
\end{aligned}
$$

where $\tilde{\boldsymbol{Q}}_{t: t+8}^{L}=\left[\begin{array}{lll}\tilde{\boldsymbol{q}}_{t: t+8}^{(1)}, \ldots, & \tilde{\boldsymbol{q}}_{t: t+8}^{(L)}\end{array}\right]$ is a set of $L$ inflow forecast scenarios; $\tilde{g}_{t}^{(l)}$ and $\tilde{h}_{t+8}^{(l)}=\left[\tilde{h}_{t+8}^{e(l)}, \tilde{h}_{t+8}^{a(l)}\right]$ are, respectively, the hydropower production during time interval $t$ and the vector of reservoir water levels at the end of $t+8$, obtained by simulating the system implementing $\boldsymbol{\rho}_{t: t+8}$ with $\tilde{\boldsymbol{q}}_{t: t+8}^{(l)} ; G$ is the total power demand, which is assumed to be the sum of the turbine power capacities (Table 1) and $\omega$ is the weight $(0 \leq \omega \leq 1)$ assigned to the penalty $F$, which is a function of the calendar month and of the reservoir water levels at the end of the 9-month forecast period, i.e. $m(t+8)$ and $h_{t+8}$, respectively. Thus, we assume that the state of the system is well described by the water storages and the time of the year. The defined objective function accounts for both the hydropower production performance during the 9month forecast period and the state of the reservoir system at the end of such period, which are quantified, respectively, by the first and second terms of the right-hand side of equation (14).

We define $F\left(m(t+8), h_{t+8}\right)$ as an approximation of the expected minimum RMSHD beyond $t+8$ conditioned on satisfying the downstream water demands. Assuming that inflow anomalies cannot be predicted beyond $t+8, F\left(m(t+8), h_{t+8}\right)$ is computed according to the following procedure:

(i) Historical inflow data are sampled to form a set of 12-month time series beginning on calendar month $m(t+9)$.

(ii) For each sampled inflow series, the approximated minimum RMSHD is found by optimizing the reservoir water level trajectory, constraining the levels at the beginning and at the end of the 12-month period to be $h_{t+8}$. Assuming that reservoir water levels can take values on a feasible discrete set, and imposing the satisfaction of downstream water demands, the trajectory minimizing RMSHD on a sampled inflow series is found via DP (Bellman 1957, Bertsekas 2000). (iii) The penalty $F\left(m(t+8), h_{t+8}\right)$ is computed as the mean of the minimum RMSHDs obtained for each sampled inflow series.

(iv) The problem solved via DP is formulated in detail in Appendix B.

The definition of the penalty function is based on the following observations:

- The penalty function has to approximate the expected future minimum RMSHD, given the available information that consists of historical inflow data and calendar month and water storages at the end of the forecast period. We used historical instead of model-generated inflow to avoid the impacts of model biases in estimating the penalties.

- Minimum RMSHDs computed on the same sampled inflow series have to be characterized by the same cumulated reservoir releases over the sampling period. For this purpose, reservoir levels at the beginning and end of the 12-month sampling period are constrained to be equal.

- By equalizing the levels at the beginning and end of the sampling period, we estimate the expected future minimum RMSHD associated with levels occurring cyclically at the end of a calendar month. Thus, monthly storage target levels can be identified. For this reason, the sampled inflow time series have to be 12 months long.

- By averaging RMSHDs obtained from a set of sampled inflow time series, we account for the observed stochasticity of inflow.

The expected RMSHD for the 9-month forecast period is evaluated by simulating the system using $L$ synthetic inflow time series and averaging the RMSHDs obtained for each series. Such stochastic evaluation implicitly accounts for input uncertainty, to enhance the robustness of the optimized decision variables. It is thus performed following the ISO paradigm (Tickle and Goulter 1994). The number of used synthetic time series $L$ is decided considering the following criteria:

Stability criterion: If simulations are iterated on several sets of inflow time series, a set of decision variables must yield similar expected RMSHD values.

Viability criterion: The computational cost of the stochastic evaluation must be acceptable.

As increasing $L$ favours stability but penalizes viability, a compromise is needed. Although the stability criterion may not guarantee reliable estimates 
of high-order inflow statistics, for reservoir optimization purposes, we are interested in the stability of the defined hydropower production metric (RMSHD).

\section{RESULTS AND DISCUSSION}

We report the results of this study in the following order. First, we illustrate the forecasts performed by the stochastic inflow model, for both calibration (1950-1989) and validation (1990-2004) periods. Then, we analyse the outcomes of applying the defined forecast-based reservoir operation to the existing water resources system (Fig. 4) for the period 2000-2008: forecast-based operation is compared to historical operation, an optimized rule curve operation (RC) strategy and the DP benchmark solution (BS). Finally, we illustrate the application of forecastbased operation to the complete water resources system, which comprises both existing and added elements, for the period 1990-2004; we carry out comparisons with the DP BS, and with two hypothetical suboptimal management strategies, as no planned operation policy is known.

The number of synthetic inflow time series used to simulate the water resources system was set to 100 , as it was the best compromise between feasibility and viability criteria (see Section 5.2).

\subsection{Stochastic inflow forecasts}

A detailed analysis of the ability of the inflow model to reproduce inflow statistics is out of the scope of this study. A thorough illustration of model performance for univariate inflow can be found in Gelati et al. (2010b). Model performance for univariate and bivariate inflow is comparable. Here, the discussion is limited to model-generated inflow forecasts.

Choosing the most appropriate model configuration includes deciding on the number of climate states to define and which ENSO indices to use as input. To balance goodness-of-fit and parameter parsimony, we used the Bayesian information criterion (BIC) (Kass and Raftery 1995, Hughes et al. 1999) as a model evaluation tool:

$$
\operatorname{BIC}(\boldsymbol{\theta})=-2 \log H\left(\boldsymbol{\theta} \mid \boldsymbol{a}_{1: T}, \boldsymbol{c}_{1: T}\right)+n \ln (K T)
$$

where $H$ is the model likelihood function, $n$ is the number of free model parameters and $K T$ is the number of inflow observations (number of inflow locations times number of time intervals). As BIC penalizes over-parameterization with a term that is proportional to the number of free parameters, preference is given to models scoring low BIC values.

A two-state model using Niño $1+2$ SST anomalies and TNI minimized BIC was chosen for this application. The inflow model was calibrated using 1950-1989 monthly time series, while the period 1990-2004 was reserved for validation.

Figures 5 and 6 compare the expected values of 1-month lead time forecasts of inflow anomalies with the corresponding observations for calibration and validation periods. Forecasts are generally more precise for Daule Peripa than for Baba, while their accuracy does not significantly change from calibration to validation. Negative inflow anomalies tend to be overestimated, mostly due to the low correlation between negative inflow anomalies and the selected ENSO indices.

Figures 5 and 6 divide inflow anomalies into three groups that correspond to normal, El Niño and La Niña conditions, according to the definition by Trenberth (1997). El Niño events correlate well with large positive inflow anomalies, while La Niña does not seem to have a significant impact on the inflow regime.

The correlation coefficients between predicted and observed inflow anomalies range from 0.21 (Baba, 9-month lead time) to 0.73 (Daule Peripa, 1-month lead time). Thus, the model has positive predictive skills for both reservoir inflow anomaly time series for all considered lead times.

\subsection{Forecast-based operation of the Daule Peripa Reservoir}

Forecast-based operation was first tested on the existing water resources system, which consists of the Daule Peripa Reservoir and its downstream hydropower plant and water users. Inflow forecasts were generated by the stochastic inflow model calibrated on the single Daule Peripa inflow time series (Gelati et al. 2010b).

The penalty function $F$ was mapped using 1950 1999 inflow data and discretizing the reservoir level at intervals of $0.1 \mathrm{~m}$. Figure 7 shows the estimated $F$ values and the target levels, which are the reservoir water levels minimizing the penalty function. The target levels indicate that it may be optimal to fill the reservoir by the end of the wet season (FebruaryMay), which provides, on average, $76 \%$ of the total annual inflow. Moreover, it may be optimal to significantly lower the water level by the beginning of the wet season: the target level at the end of January 
Daule Peripa (calibration)
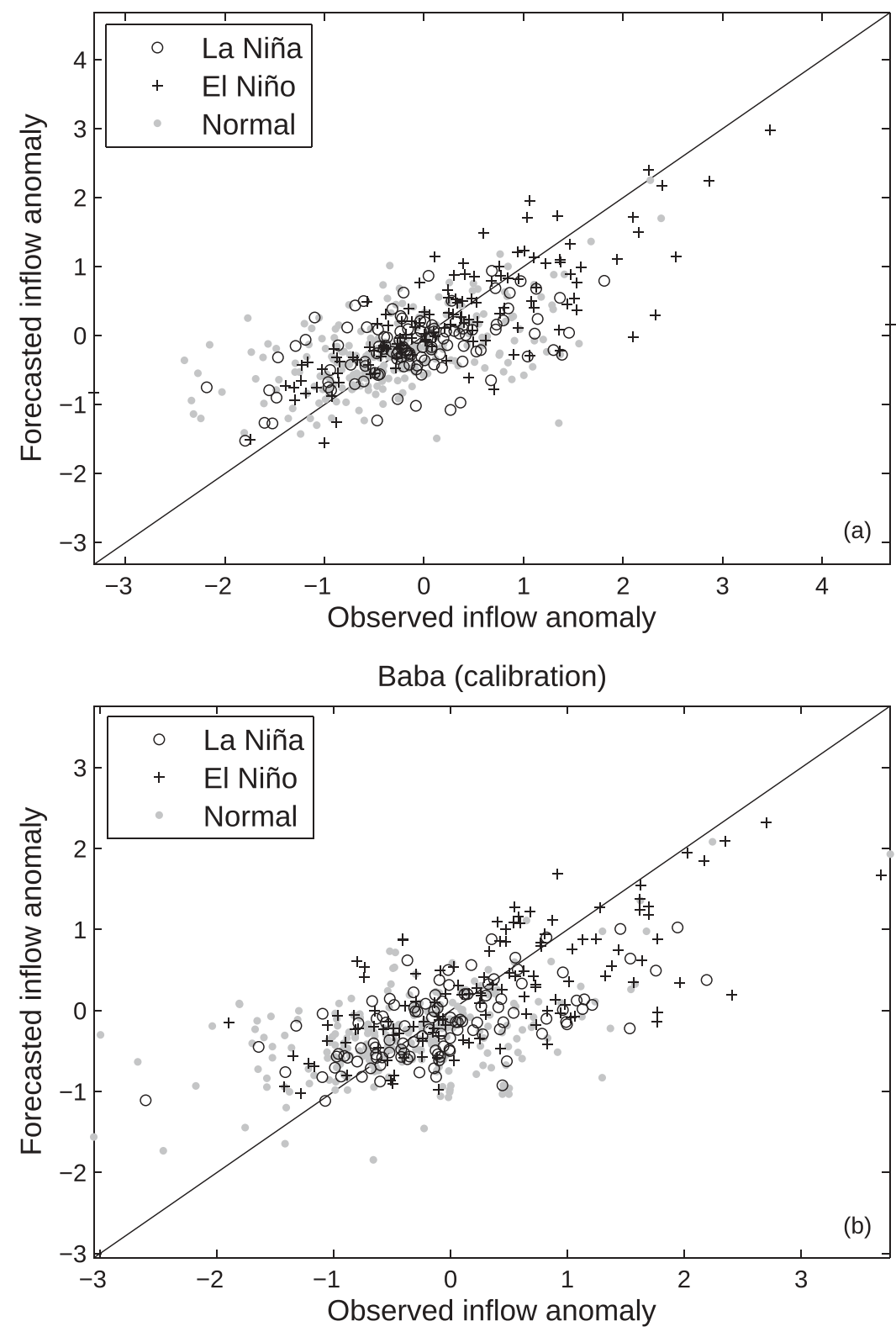

Fig. 5 Expected values of 1-month lead time inflow anomaly forecasts $v s$ observations for (a) Daule Peripa and (b) Baba. Calibration period: $1950-1989$.

corresponds to leaving $74 \%$ of active storage empty. It may be critical to empty the reservoir after the end of the wet season, as it would leave no stored water for the following dry season (June-January). Also, it may be damaging to have the reservoir full at the end of the dry season, as part of the wet season inflow could be spilled and thus not be turbinated. Spills are non-turbinated water releases occurring when the downstream water demands are already satisfied.

The optimal value of $\omega(0.4)$, which is the weight assigned to the penalty term when computing the objective function, was determined by minimizing the overall expected RMSHD obtained by operating the Daule Peripa Reservoir for the period 1950-1999. For 2000-2008, forecast-based operation was implemented using both $\omega=0.4$ and $\omega=0$, to evaluate the effect of including the penalty term in the objective function.

Table 2 summarizes the performance of forecastbased operation with (FP) and without (FO) penalty, historical operation (HO), RC as optimized by Gelati et al. (2011) and BS computed via DP. The HO was probably performed on sub-monthly time scales that are typical for hydropower systems. This must be 
Daule Peripa (validation)

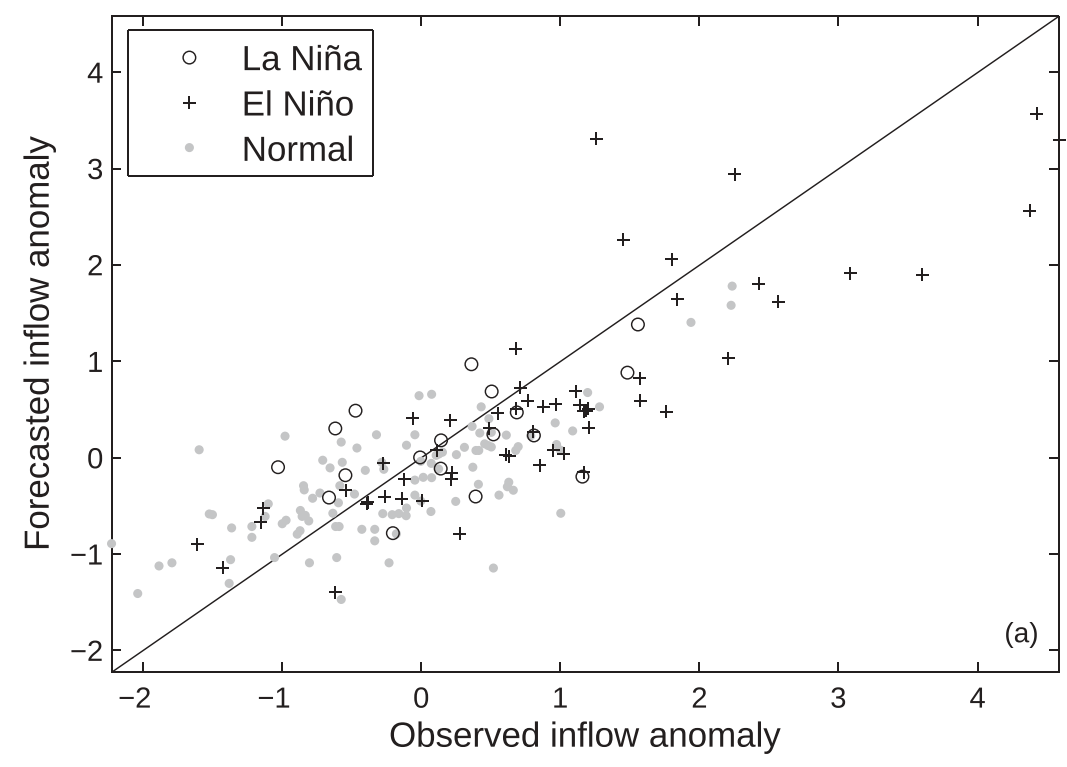

Baba (validation)

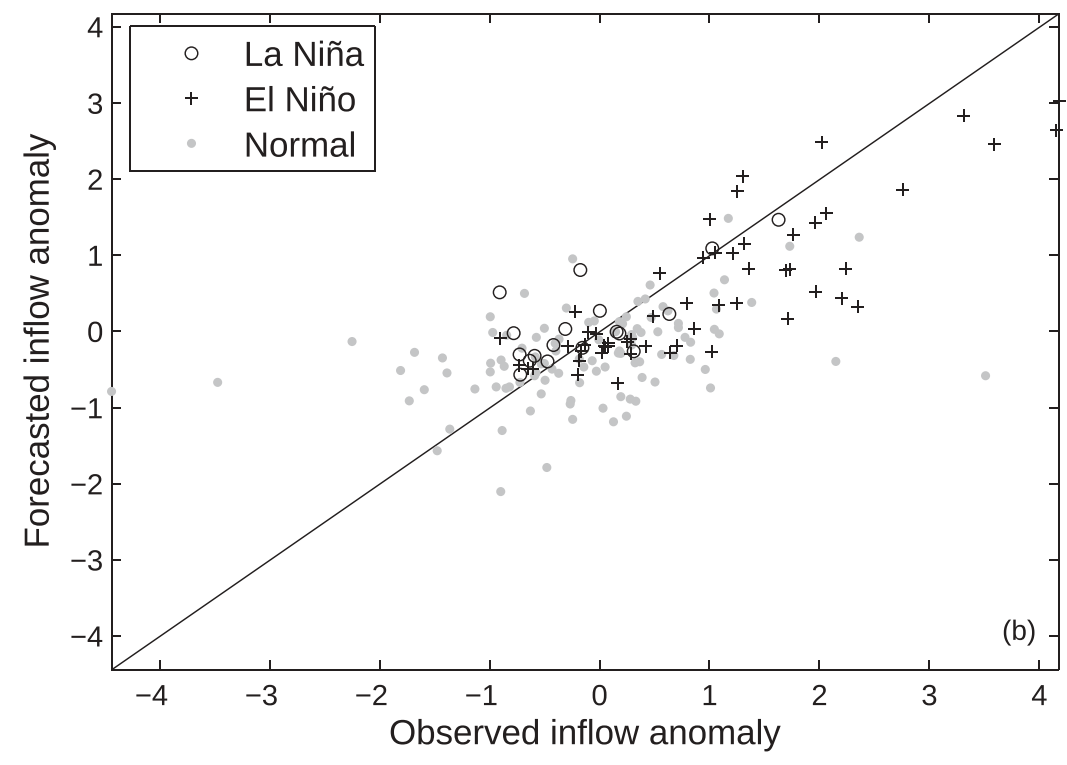

Fig. 6 Expected values of 1-month lead time inflow anomaly forecasts $v s$ observations for (a) Daule Peripa and (b) Baba. Validation period: $1990-2004$.

considered when comparing $\mathrm{HO}$ with the other tested operation policies, which are defined on monthly time intervals. The RC operation, which determines reservoir release as a function of current storage and calendar month, is included in this comparison to benchmark FO and FP against a hypothetical RC policy that does not exploit inflow forecasts. BS is found via DP by assuming perfect knowledge of 2000-2008 inflow, as described in Appendix B. BS approximates the minimum possible expected RMSHD, conditioned on satisfying the downstream water demand. Although this is an overestimation as the reservoir water level is discretized, it is realistic since we used a high water level resolution $(0.1 \mathrm{~m})$ to find BS. Thus, BS can benchmark reductions in expected RMSHD with respect to $\mathrm{HO}$ : RC, FO and FP yield $31 \%, 32 \%$ and $57 \%$ of the maximum theoretical reduction estimated by $\mathrm{BS}$, respectively. FP outperforms $\mathrm{HO}, \mathrm{FO}$ and $\mathrm{RC}$ considering both expected RMSHD and average generated power. With respect to $\mathrm{HO}$, the increases in hydropower production obtained by $\mathrm{RC}, \mathrm{FO}$ and $\mathrm{FP}$ are $1.1 \%$, $0.2 \%$ and $3.6 \%$, while the theoretical increase given by $\mathrm{BS}$ is $5.7 \%$. 


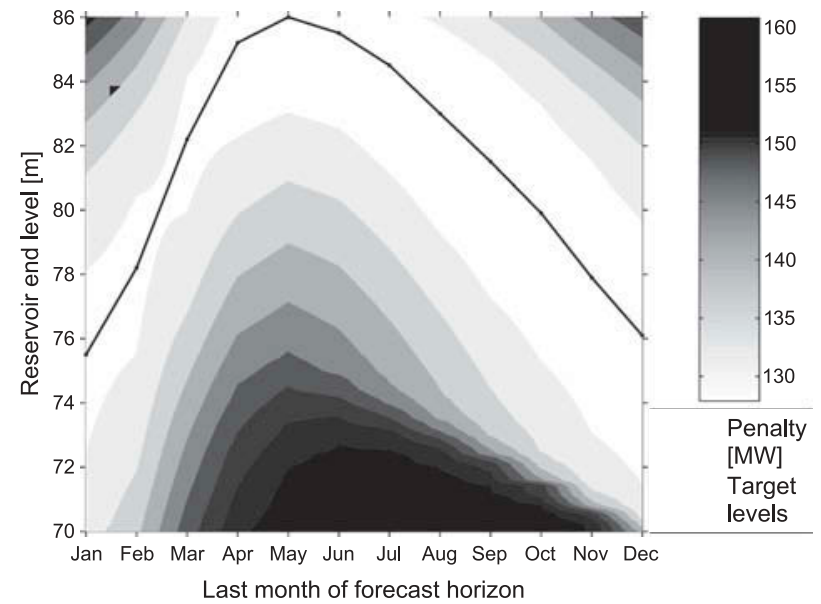

Fig. 7 Contour map of the penalty function for Daule Peripa estimated using 1950-1999 inflow data.

Table 2 Daule Peripa Reservoir operation performance indicators for the period 2000-2008.

\begin{tabular}{lllll}
\hline Operation & $\begin{array}{l}\text { Expected } \\
\text { RMSHD } \\
(\mathrm{MW})\end{array}$ & $\begin{array}{l}\text { Average } \\
\text { power } \\
(\mathrm{MW})\end{array}$ & $\begin{array}{l}\text { Average } \\
\text { spill } \\
\left(\mathrm{m}^{3} / \mathrm{s}\right)\end{array}$ & $\begin{array}{l}\text { Downstream } \\
\text { deficit frequency } \\
(\%)\end{array}$ \\
\hline HO & 147.0 & 70.6 & 2.3 & 0 \\
$\mathrm{FO}$ & 144.7 & 70.7 & 0 & 0 \\
$\mathrm{FP}$ & 142.9 & 73.1 & 1.7 & 0 \\
$\mathrm{RC}$ & 144.8 & 71.4 & 1.5 & 0 \\
$\mathrm{BS}$ & 139.8 & 74.6 & 0 & 0 \\
\hline
\end{tabular}

HO: historical operation; FO and FP: forecast-based operation without and with penalty, respectively; RC: rule curve operation as optimized by Gelati et al. (2011); BS: dynamic programming benchmark solution.

Both FO and FP meet the Daule Peripa downstream water demand for all time intervals. Indeed, the minimization of expected RMSHD avoids extremely low releases; thus, the satisfaction of the downstream water demand does not need to be explicitly defined in the objective function. Compared to RC, FO does not yield a noticeable improvement. In fact, FO produces less hydropower than RC. Instead, FP proves to perform better than the RC optimized by Gelati et al. (2011) in terms of both objective function score and average hydropower production. Introducing the penalty function appears to significantly benefit forecast-based operation.

Figure 8 reports the reservoir water levels obtained with the tested operations and the observed monthly inflow for the 2000-2008 period. As mentioned when discussing the estimated penalty term, according to BS, it is optimal to fill the reservoir by the end of the wet season. Moreover, BS water levels decrease during the dry seasons, to leave enough empty reservoir volume for storing the following wet season inflow, thereby minimizing the probability of spills. HO and FO partially succeed in filling the reservoir at the end of the wet season until 2003. The anomalously low inflow of 2004 is over-predicted by the stochastic inflow model, because of the low correlation between negative inflow anomalies and ENSO indices. In the following years, $\mathrm{HO}$ and $\mathrm{FO}$ water levels fluctuate far below the maximum reservoir level. HO recovers part of the gap with BS only in 2008 by significantly increasing the water level at the end of the wet season, while FO does not recover after 2004, thus proving its short-sightedness. Indeed, FO does not account for what happens beyond the 9month forecast period. In contrast, FP uses both shortand long-term information, as it combines inflow forecasts with penalizing deviations from target water levels. Consequently, the FP water level falls less dramatically than FO and HO levels for 2004 and recovers faster afterwards. Despite the misprediction of the 2004 drought, the penalty function hinders excessive releases and favours the recovery of high water levels at the end of the wet season.

The penalty function accounts for the benefits of preserving future high hydraulic heads and thus promotes an energy-efficient use of water. It also increases the spill frequency (Table 2). However, FP reduces by $30 \%$ the amount of water spilled by HO.

\subsection{Forecast-based operation of the Daule Peripa and Baba reservoir system}

After being tested on the Daule Peripa Reservoir, forecast-based operation was applied to the planned complete water resources system (Fig. 4) from 1990 to 2004. The inflow forecasts were generated by the multivariate inflow model presented in Section 3.

As for the single-reservoir case, we estimated the penalty function $F$ using inflow data from a period preceding the implementation of forecast-based operation, i.e. 1950-1989. We discretized the water levels of Daule Peripa and Baba reservoirs at intervals of $0.1 \mathrm{~m}$ and $2.5 \mathrm{~m}$, respectively. Such discretizations are characterized by approximately the same volume resolution. Figure 9 shows marginalizations of the penalty function for the reservoirs: each plot maps $F$ for a reservoir, given that the other reservoir water levels are fixed at their monthly target values. Figure 9(a) maps the penalty as a function of calendar month and Daule Peripa water level, given that the Baba water level is at its target value for the considered month. Figure 9(b) is obtained in the same manner by swapping the reservoirs. The marginal penalty map of Daule 

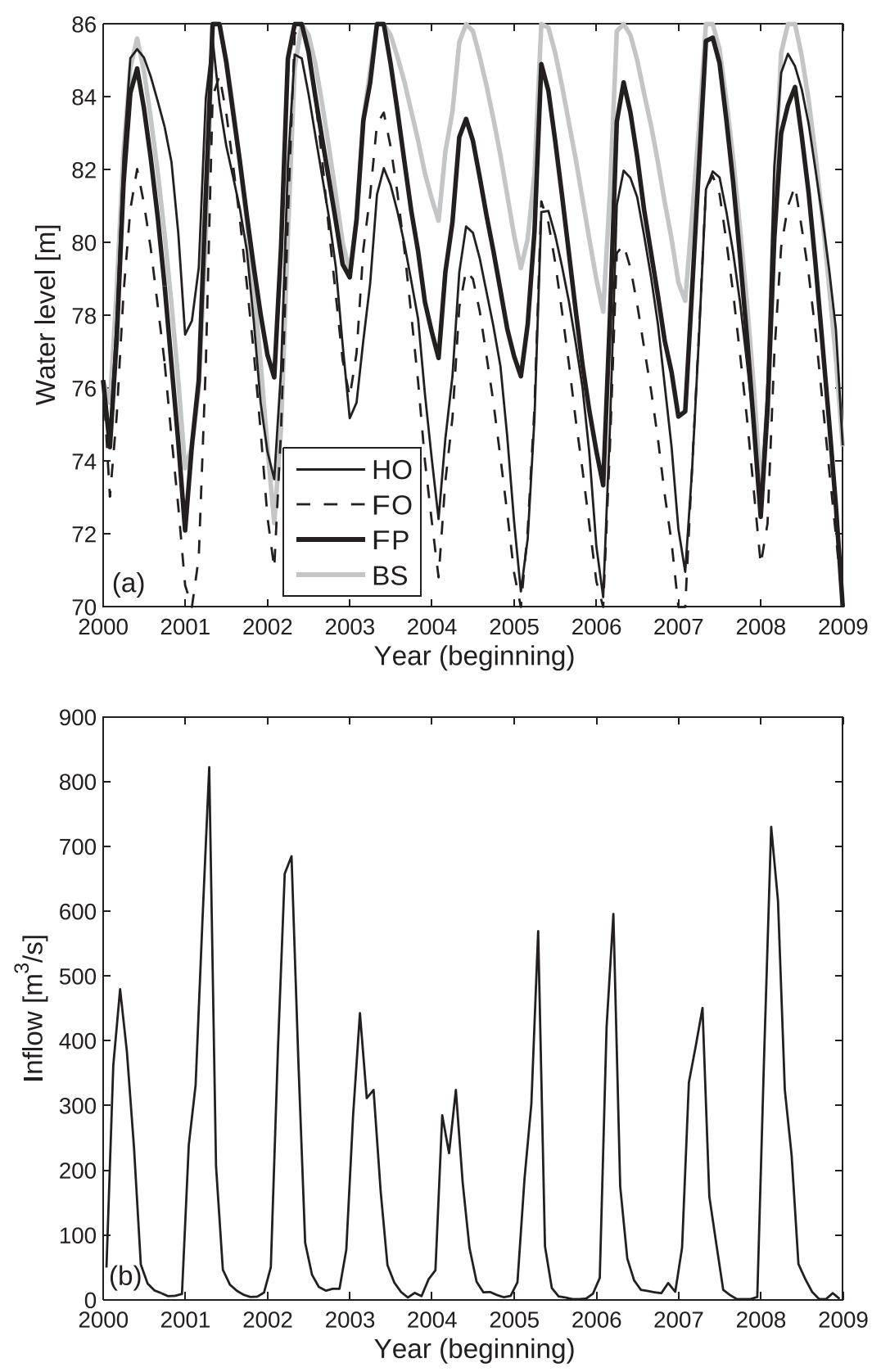

Fig. 8 Time series for Daule Peripa between 2000 and 2008: (a) water levels of the simulated operations and (b) observed inflow.

Peripa is similar to that estimated for the single-reservoir case. Exceptions are the December-January target water levels, which are lower in the two-reservoir case. Due to the water transferred from Baba, which increases the inflow to Daule Peripa, a larger part of reservoir volume needs to be empty to store the wet season inflow. The marginal penalty map for Baba indicates that it is optimal to keep the reservoir full most of the time, and to lower the water level during the dry season by transferring water to Daule Peripa. However, Fig. 9(b) does not show a clear preference pattern for Baba water levels. This may be due to the small storage capacity of the Baba Reservoir, whose active storage volume is $3.4 \%$ of the total system storage capacity.

The optimal value of the weight $\omega$ assigned to the penalty function was found to be 0.2 by optimizing the system forecast-based operation for the period 1950 1989. Thus, the penalty function is given less importance than in the single-reservoir case. This may be due to the water from Baba that facilitates the recovery of high hydraulic heads at Daule Peripa after dry periods. 

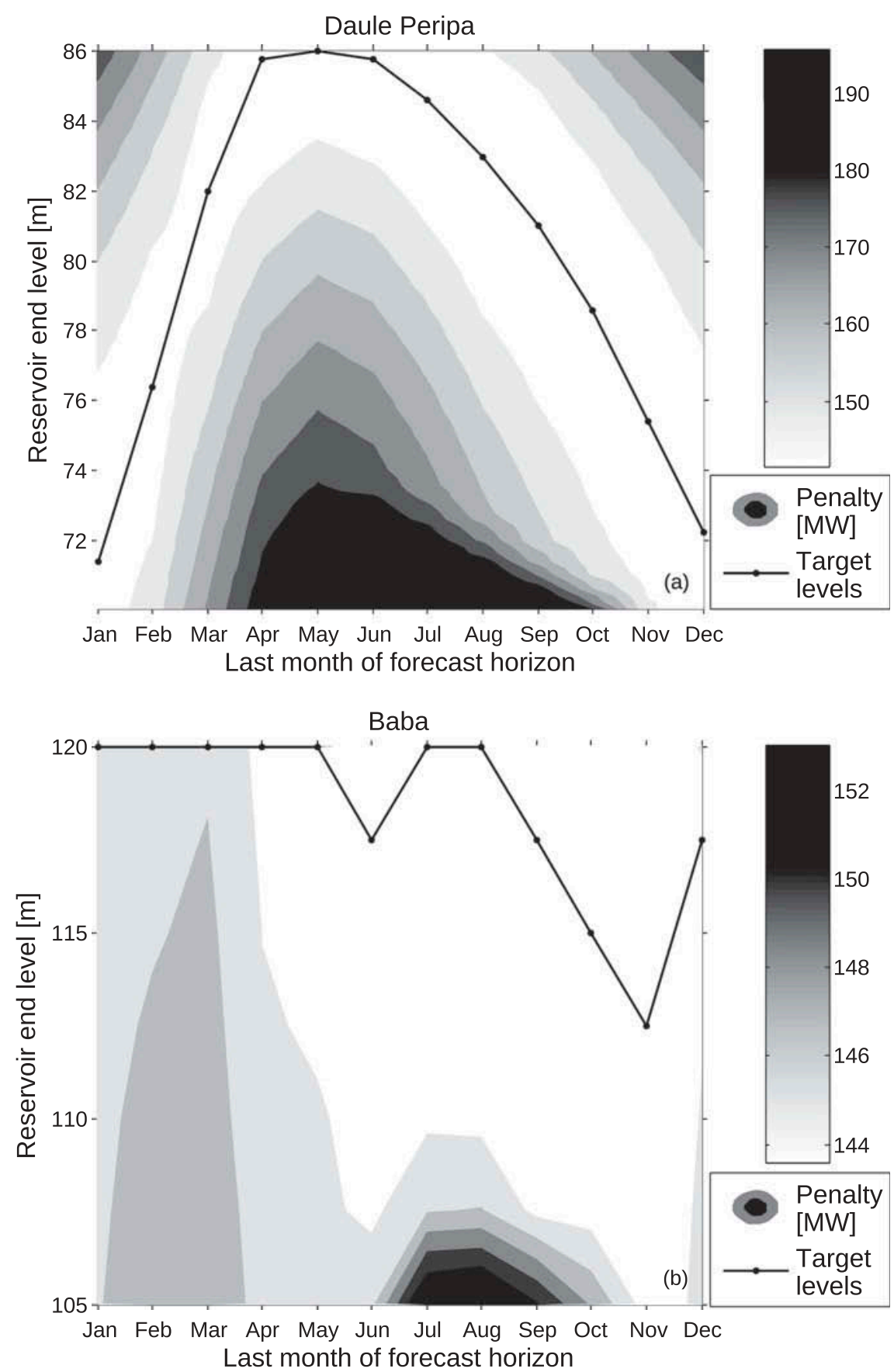

Fig. 9 Contour map of the marginal penalty functions estimated using 1950-1989 inflow data: (a) Daule Peripa and (b) Baba.

As no planned management policy is known for the complete system, forecast-based operation (FP) was compared with the DP BS and two hypothetical operation strategies that were conceived to mimic suboptimal, however likely, management of the added Baba Reservoir. Both hypothetical strategies assume that the Baba Reservoir is assigned a fixed operation policy, regardless of inflow forecasts and water storages, while the operation of Daule Peripa is forecast based and optimized, as follows:

- maximum transfer (MT) strategy transfers as much water as possible to Daule Peripa at each time interval;

- maximum head (MH) strategy transfers water only if the Baba Reservoir is full. 
Table 3 Operational performance indicators of the complete water resources system for 1990-2004.

\begin{tabular}{|c|c|c|c|c|c|c|c|c|}
\hline & \multirow{2}{*}{$\frac{\text { Expected RMSHD }}{\text { Total (MW) }}$} & \multicolumn{3}{|c|}{ Average power } & \multicolumn{2}{|l|}{ Average spill } & \multicolumn{2}{|c|}{$\begin{array}{l}\text { Downstream deficit } \\
\text { frequency }\end{array}$} \\
\hline & & Total (MW) & $\begin{array}{l}\text { Daule Peripa } \\
\text { (MW) }\end{array}$ & Baba (MW) & $\begin{array}{l}\text { Daule Peripa } \\
\left(\mathrm{m}^{3} / \mathrm{s}\right)\end{array}$ & $\begin{array}{l}\mathrm{Baba} \\
\left(\mathrm{m}^{3} / \mathrm{s}\right)\end{array}$ & $\begin{array}{l}\text { Daule } \\
\text { Peripa (\%) }\end{array}$ & Baba (\%) \\
\hline MT & 145.6 & 144.7 & 126.2 & 18.5 & 64.5 & 8.6 & 0 & 0.6 \\
\hline BH & 139.5 & 152.0 & 125.2 & 26.8 & 63.4 & 11.2 & 0 & 0 \\
\hline FP & 135.2 & 155.3 & 129.0 & 26.3 & 52.2 & 11.2 & 0 & 0.6 \\
\hline BS & 131.3 & 159.3 & 133.3 & 26.0 & 44.3 & 9.6 & 0 & 0 \\
\hline
\end{tabular}

MT: maximum transfer strategy; MH: maximum head strategy; FP: forecast-based operation; BS: dynamic programming benchmark solution.

The MT strategy maximizes the amount of water transferred from Baba to Daule Peripa, while MH maximizes the hydraulic heads at the added hydropower plant.

Table 3 reports the performance indicators of MT, MH, FP and BS. FP outperforms both hypothetical operation strategies, among which $\mathrm{MH}$ yielded the best results. MT minimizes the spill from Baba, but yields low hydraulic heads at the added hydropower plant, thus negatively affecting hydropower production. Moreover, MT yields the largest average spill from Daule Peripa. Maximizing the amount of transferred water without considering the water level of Daule Peripa causes an inefficient temporal allocation of water. The MH strategy is characterized by large average spills from both reservoirs. However, by maximizing hydraulic heads, $\mathrm{MH}$ yields the largest hydropower production at the added plant and outperforms MT. FP causes a large average spill from Baba, but significantly reduces the spill from Daule Peripa, thus increasing the production at the existing hydropower plant compared to $\mathrm{MT}$ and $\mathrm{MH}$. Moreover, power generation at the added plant is only slightly lower than for $\mathrm{MH}$, thus implying that FP transfers water from Baba to Daule Peripa at relatively high hydraulic heads.

BS indicates the system operation minimizing expected RMSHD, given the reservoir water level discretizations. Compared to FP, BS reduces the spill from both reservoirs, significantly increases hydropower production at the existing plant and slightly reduces the production at the added plant. This means that, although BS transfers water at lower hydraulic heads than FP, the optimal temporal water allocation of BS yields better overall results.

While the Daule Peripa downstream water demand is always met, the FP fails to meet the Baba downstream demand in 1 month during the evaluation period. An additional objective accounting for the satisfaction of downstream demands may allow reduction of the deficit frequency and analysis of the trade-off between hydropower production and water supply reliability. However, the low FP water supply deficit frequency $(0.6 \%)$ could be acceptable and might not justify the formulation of a multiobjective optimization problem. Moreover, the predicted Baba water supply deficit is due to the combined effect of the following factors:

- the relatively small storage capacity of the Baba Reservoir and

- the tendency of the inflow forecast model to overestimate negative anomalies (Section 6.1).

Figure 10 illustrates the water level and release time series of the Daule Peripa Reservoir for MH, FP and BS. FP reservoir levels are generally close to BS levels, except for 2004, which is the driest year of the considered period. As for the single-reservoir case, the inflow model mispredicts the anomalously low inflow of 2004. No inflow data are available for Baba after 2004; thus, we are not able to test the impact of the drought on system operation during the subsequent years. The MH generally fails to empty the Daule Peripa Reservoir at the end of the dry season, thus provoking larger spills than FP and BS (Fig. 10(b)). Such larger spills are responsible for most of the gap between MH and FP and are due to the suboptimal temporal allocation of water resulting from the fixed operation strategy of Baba Reservoir. The joint operation of the two reservoirs enhances water-use efficiency compared to a separate management strategy such as $\mathrm{MH}$.

The BS suggests that spills cannot be avoided in several circumstances. The limited storage capacity of Baba, if compared to its average annual inflow, hinders the storage of large amounts of water during the wet season and their transfer to the Daule Peripa Reservoir during the dry season. The inclusion of Baba will increase inflow by $60 \%$ and storage capacity by only $3.5 \%$ with respect to the existing system. However, the 

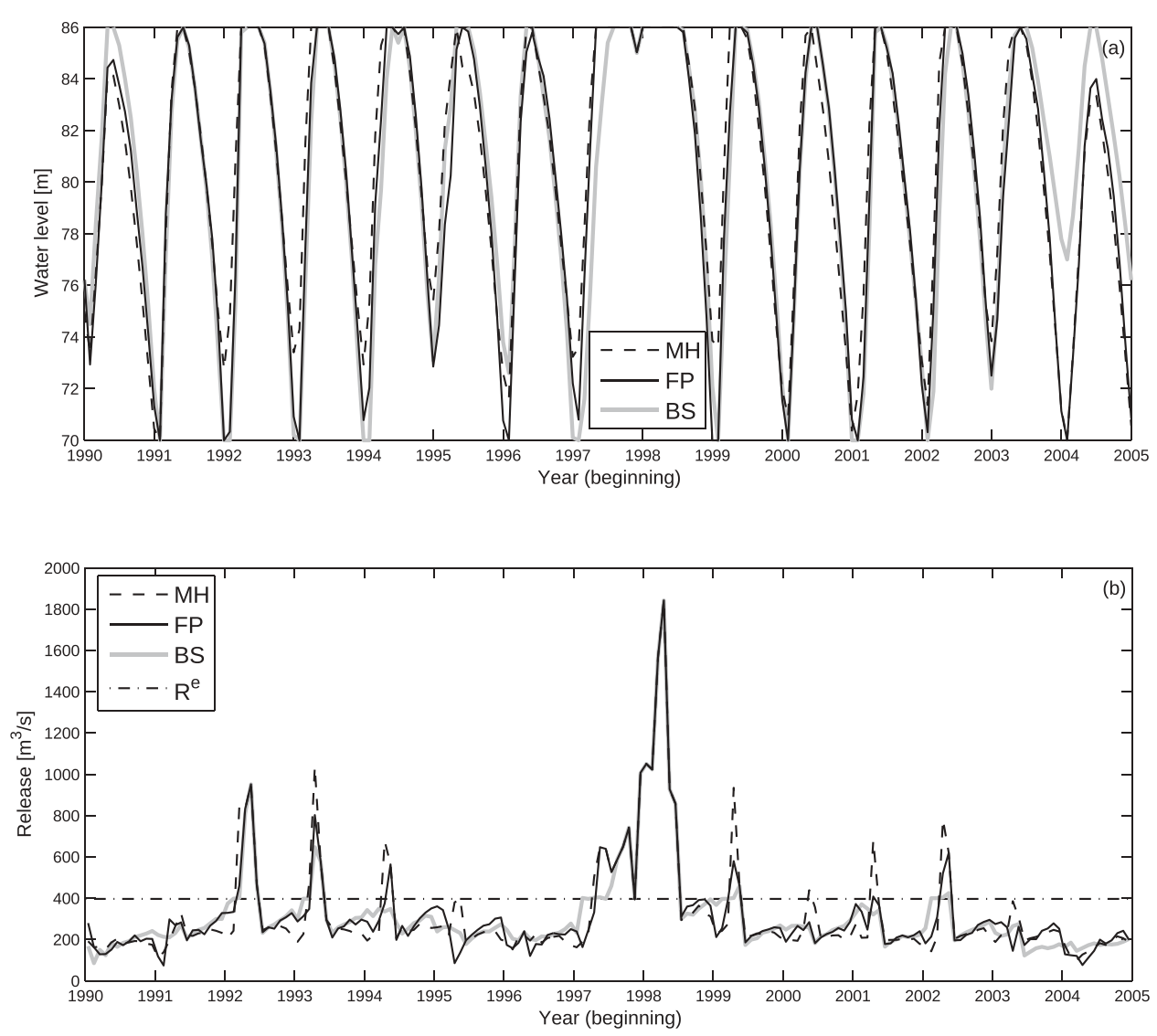

Fig. 10 Daule Peripa operations for the period 1990-2004: (a) reservoir water levels and (b) releases with the turbine hydraulic capacity $R^{e}$.

large spills from Daule Peripa simulated for the 1997/98 El Niño event are due not only to the lack of storage, but also to an operational factor. As no information is available about downstream flood vulnerability or flood prevention policies, we did not introduce any flood protection criterion in the reservoir operation. Flood risk might be accounted for by penalizing large releases or adding a flood protection objective when optimizing the operation.

\section{SUMMARY AND CONCLUSIONS}

In the presented methodology, which is built on the work by Gelati et al. (2011), inflow forecasts produced using ENSO indices and monthly storage targets were combined to optimize the forecast-based operation of the Daule Peripa and Baba water resources system.

The system, located in western Ecuador, consists of the existing Daule Peripa Reservoir serving a hydropower plant and of the planned Baba Reservoir supplying a hydropower plant that will be built on a transfer to Daule Peripa. Both reservoirs are characterized by downstream water demands that are aggregates of household water supply, irrigation and ecological flows. The ENSO influences the streamflow regime of the Daule, Peripa and Baba rivers that supply the reservoirs. El Niño events are well correlated with anomalously large inflow, while La Niña does not significantly affect inflow.

Inflow forecasts were performed by a multivariate stochastic model mimicking climate-induced inflow regime shifts and using ENSO indices as covariates. The SST anomaly of the Niño $1+2$ region and the TNI, which measures the westward SST anomaly gradient over the equatorial Pacific Ocean, constitute the climatic input. Inflow was forecast for lead times of 1-9 months, according to the currently issued ENSO forecasts. Anomalously high inflow during intense El Niño events was predicted more accurately than anomalously low inflow, which was generally overestimated.

Forecast-based reservoir operation is defined to optimize monthly releases using ENSO forecasts. As data availability forced the development of methodologies using monthly time intervals, this study aims at showing potential operational 
improvements by using ENSO-driven monthly inflow forecasts. However, operational hydropower simulation and optimization tools should be defined at shorter time scales. At the beginning of each month, reservoir releases are optimized for the following 9 months. The releases of the first month are implemented, the state of the system is updated and the procedure is iterated at the beginning of the following month. Releases are optimized by a GA. The optimization is defined as a minimization problem, where the objective function is a weighted sum of the expected RMSHD during the 9-month forecast horizon and a term penalizing deviations from reservoir storage targets at the end of the forecast period. Thus, the evaluation of the operation during the forecast period is integrated with a measure of future performance based on the final storage levels. To account for forecast uncertainty, each set of decision variables is evaluated using a number of inflow forecast scenarios as input to the reservoir system simulation model.

Forecast-based operation was first applied to the existing Daule Peripa Reservoir. It outperformed both 2000-2008 historical management and an optimized RC policy that determines reservoir release as a function of storage and calendar month. These results indicate the potential benefits of using ENSO forecasts in reservoir operation. Moreover, penalizing deviations from monthly storage targets enhanced water-use efficiency by preserving high future hydraulic heads for hydropower generation.

Forecast-based operation was then applied to the complete planned water resources system. As no planned operation policy is known, forecastbased operation was compared to two hypothetical fixed management strategies. These strategies operated the planned Baba Reservoir regardless of inflow forecasts or storage levels, while optimized forecast-based operation was applied to Daule Peripa. The joint operation of the two reservoirs outperformed the hypothetical management strategies.

Assuming perfect knowledge of future inflow, we derived an optimal solution via DP. Such a solution represents the maximum possible operational improvement according to the defined objectives and was used to benchmark the performance of the tested operation policies.

We identified the following research directions, which are specific to this case study:
- The accuracy of inflow forecasts may be enhanced by pursuing ENSO indices that correlate better with anomalously low inflow.

- Forecast-based operation might benefit from accounting for downstream demand satisfaction by adding an objective to the optimization problem.

- Obtaining information about the flood vulnerability of the downstream regions would allow including flood protection among the operational objectives.

The proposed methodology should be tested on larger systems in order to be further validated. While system complexity would be increased by adding reservoirs, the defined multivariate inflow modelling approach would limit the number of required inflow scenario simulations. Indeed, although more inflow time series would have to be modelled, they would be conditioned on a common climate state process. Increasing system complexity may lead to a multiobjective optimization problem, which could be solved by a multi-objective search algorithm, examples of which may be found in Oliveira and Loucks (1997), Sharif and Wardlaw (2000) and Chen (2003).

\section{REFERENCES}

Akintug, B. and Rasmussen, P.F., 2005. A Markov switching model for annual hydrologic time series. Water Resources Research, 41 (9), W09424. doi:10.1029/2004WR003605.

Baum, L.E., et al., 1970. A maximization technique occurring in the statistical analysis of probabilistic functions of Markov chains. The Annals of Mathematical Statistics, 41 (1), 164-171. doi:10.1214/aoms/1177697196.

Bellman, R., 1957. Dynamic programming. Princeton, NJ: Princeton University Press.

Bellone, E., Hughes, J.P., and Guttorp, P., 2000. A hidden Markov model for downscaling synoptic atmospheric patterns to precipitation amounts. Climate Research, 15 (1), 1-12. doi:10.3354/cr015001.

Bertsekas, D., 2000. Dynamic programming and optimal control. Belmont, MA: AthenaScientific.

Cappè, O., Moulines, E., and Rydèn, T., 2005. Inference in hidden Markov models. New York: Springer Series in Statistics.

Celeste, A.B., Suzuki, K., and Kadota, A., 2008. Integrating longand short-term reservoir operation models via stochastic and deterministic optimization: case study in Japan. Journal of Water Resources Planning and Management, 134 (5), 440448. doi:10.1061/(ASCE)0733-9496(2008)134:5(440).

Chen, L., 2003. Real coded genetic algorithm optimization of long term reservoir operation. Journal of the American Water Resources Association, 39 (5), 1157-1165. doi:10.1111/ j.1752-1688.2003.tb03699.x.

Dempster, A.P., Laird, N.M., and Rubin, D.B., 1977. Maximum likelihood from incomplete data via the EM algorithm. Journal of the Royal Statistical Society Series BMethodological, 39 (1), 1-38.

Gelati, E., 2010. Integrating climatic information in water resources modelling and optimisation. Thesis (PhD). Department of Environmental Engineering, Technical University of Denmark. 
Gelati, E., Madsen, H., and Rosbjerg, D., 2010b. Markov-switching model for nonstationary runoff conditioned on El Niño information. Water Resources Research, 46, W02517. doi:10.1029/ 2009WR007736.

Gelati, E., Madsen, H., and Rosbjerg, D., 2011. Stochastic reservoir optimization using El Niño information: case study of Daule Peripa, Ecuador. Hydrology Research, 42 (5), 413-431. doi:10.2166/nh.2011.009.

Gelati, E., et al., 2010a. Downscaling atmospheric patterns to multisite precipitation amounts in southern Scandinavia. Hydrology Research, 41 (3-4), 193-210. doi:10.2166/nh.2010.114.

Georgakakos, A., 1989. The value of streamflow forecasting in reservoir operation. Journal of the American Water Resources Association, 25 (4), 789-800. doi:10.1111/j.1752-1688.1989. tb05394.x.

Goldberg, D.E., 1989. Genetic algorithms in search, optimization, and machine learning. Reading, MA: Addison-Wesley.

Gopalakrishnan, G., Minsker, B.S., and Goldberg, D., 2001. Optimal sampling in a noisy genetic algorithm for risk-based remediation design. In: D. Phelps and G. Sehlke, eds. Bridging the gap: meeting the world's water and environmental resources challenges. Proceedings world water and environmental resources congress. Washington, DC: ASCE.

Hamilton, J.D., 1989. A new approach to the economic analysis of nonstationary time series and the business cycle. Econometrica, 57 (2), 357-384. doi:10.2307/1912559.

Holland, J.H., 1992. Adaptation in natural and artificial systems. Cambridge, MA: Massachusetts Institute of Technology.

Hughes, J.P. and Guttorp, P., 1994. A class of stochastic models for relating synoptic atmospheric patterns to regional hydrologic phenomena. Water Resources Research, 30 (5), 1535-1546. doi:10.1029/93WR02983.

Hughes, J.P., Guttorp, P., and Charles, S.P., 1999. A non-homogeneous hidden Markov model for precipitation occurrence. Journal of the Royal Statistical Society: Series C (Applied Statistics), 48 (1), 15-30. doi:10.1111/1467-9876.00136.

Kapelan, Z., et al., 2006. Risk- and robustness-based solutions to a multi-objective water distribution system rehabilitation problem under uncertainty. Water Science \& Technology, 53 (1), 61-75. doi:10.2166/wst.2006.008.

Karamouz, M. and Houck, M.H., 1987. Comparison of stochastic and deterministic dynamic programming for reservoir operating rulegeneration. Journal of the American Water Resources Association, 23 (1), 1-9. doi:10.1111/j.1752-1688.1987.tb00778.x.

Kass, R.E. and Raftery, A.E., 1995. Bayes factors. Journal of the American Statistical Association, 90 (430), 773-795. doi:10.1080/01621459.1995.10476572.

Labadie, J., Lazaro, R., and Morrow, D., 1981. Worth of short-term rainfall forecasting for combined sewer overflow control. Water Resources Research, 17 (5), 1489-1497. doi:10.1029/ WR017i005p01489.

Labadie, J.W., 2004. Optimal operation of multireservoir systems: state-of-the-art review. Journal of Water Resources Planning and Management, 130 (2), 93-111. doi:10.1061/(ASCE)07339496(2004)130:2(93).

Mishalani, N. and Palmer, N., 1988. Forecast uncertainty in water supply reservoir operation. Journal of the American Water Resources Association, 24 (6), 1237-1245. doi:10.1111/ j.1752-1688.1988.tb03043.x.

Mujumdar, P.P. and Ramesh, T.S.V., 1997. Real-time reservoir operation for irrigation. Water Resources Research, 33 (5), 1157 1164. doi:10.1029/96WR03907.

Mujumdar, P.P. and Teegavarapu, R., 1998. A short-term reservoir operation model for multicrop irrigation. Hydrological Sciences Journal, 43 (3), 479-494. doi:10.1080/ 02626669809492139 .
Ngo, L.L., Madsen, H., and Rosbjerg, D., 2007. Simulation and optimisation modelling approach for operation of the Hoa Binh reservoir, Vietnam. Journal of Hydrology, 336 (3-4), 269-281. doi:10.1016/j.jhydrol.2007.01.003.

Oliveira, R. and Loucks, D.P., 1997. Operating rules for multi-reservoir systems. Water Resources Research, 33 (4), 839-852. doi:10.1029/96WR03745.

Rabiner, L.R., 1989. A tutorial on hidden Markov models and selected applications in speech recognition. Proceedings of the IEEE, 77 (2), 257-286. doi:10.1109/5.18626.

Rani, D. and Moreira, M.M., 2010. Simulation-optimization modeling: a survey and potential application in reservoir systems operation. Water Resources Management, 24 (6), 1107-1138. doi:10.1007/s11269-009-9488-0.

Robertson, A.W., Kirshner, S., and Smyth, P., 2004. Downscaling of daily rainfall occurrence over northeast Brazil using a hidden Markov model. Journal of Climate, 17 (22), 4407-4424. doi:10.1175/JCLI-3216.1.

Roefs, T.G. and Bodin, L.D., 1970. Multireservoir operation studies. Water Resources Research, 6 (2), 410-420. doi:10.1029/ WR006i002p00410.

Sharif, M. and Wardlaw, R., 2000. Multireservoir systems optimization using genetic algorithms: case study. Journal of Computing in Civil Engineering, 14 (4), 255-263. doi:10.1061/(ASCE)0887-3801(2000)14:4(255).

Simonovic, S.P., 1992. Reservoir systems analysis: closing gap between theory and practice. Journal of Water Resources Planning and Management, 118 (3), 262-280. doi:10.1061/ (ASCE)0733-9496(1992)118:3(262).

Simonovic, S.P. and Burn, D.H., 1989. An improved methodology for short-term operation of a single multipurpose reservoir. Water Resources Research, 25 (1), 1-8. doi:10.1029/ WR025i001p00001.

Smalley, J.B. and Minsker, B.S., Goldberg, D.E., 2000. Risk-based in situ bioremediation design using a noisy genetic algorithm. Water Resources Research, 36 (10), 3043-3052. doi:10.1029/ 2000WR900191.

Tickle, K.S. and Goulter, I.C., 1994. Uncertainty in reservoir operation optimisation. In: D.G. Fontane and H.N. Tuvel, eds. Water policy and management: Solving the problems. New York: ASCE, 3043-3052.

Trenberth, K.E., 1997. The definition of El Niño. Bulletin of the American Meteorological Society, 78 (12), 2771-2777. doi:10.1175/1520-0477(1997)078<2771:TDOENO>2.0.CO;2.

Trenberth, K.E. and Stepaniak, D.P., 2001. Indices of El Niño evolution. Journal of Climate, 14 (8), 1697-1701. doi:10.1175/1520-0442 (2001)014<1697:LIOENO >2.0.CO;2.

Vuille, M., Bradley, R.S., and Keimig, F., 2000. Climate variability in the Andes of Ecuador and its relation to tropical Pacific and Atlantic sea surface temperature anomalies. Journal of Climate, 13 (14), 2520-2535. doi:10.1175/1520-0442(2000)013<2520: CVITAO $>2.0 . \mathrm{CO} ; 2$.

WCD (World Commission on Dams), 2000. Dams and development: a new framework for decision-making. London: Earthscan Publications Ltd.

Wu, J., et al., 2006. A comparative study of Monte Carlo simple genetic algorithm and noisy genetic algorithm for cost-effective sampling network design under uncertainty. Advances in Water Resources, 29 (6), 899-911. doi:10.1016/j.advwatres. 2005.08.005.

Wurbs, R.A., 1993. Reservoir-system simulation and optimization models. Journal of Water Resources Planning and Management, 119 (4), 455-472. doi:10.1061/(ASCE)07339496(1993)119:4(455).

Yeh, W., 1985. Reservoir management and operations models: a state-of-the-art review. Water Resources Research, 21 (12), 1797-1818. doi:10.1029/WR021i012p01797. 


\section{APPENDIX A}

\section{The EM algorithm}

Let $\hat{z}^{(n)}$ and $\hat{\boldsymbol{\theta}}^{(n)}$ be, respectively, the estimate of the generic parameter $z$ and the full set of parameter estimates at the $n$th iteration of the EM algorithm. Each iteration of the EM algorithm consists of two steps, namely the expectation and maximization steps.

The expectation step computes the conditional expected value of the log-likelihood function given the previous set of parameter estimates $\hat{\boldsymbol{\theta}}^{(n-1)}$ :

$$
\begin{aligned}
\mathrm{E}\{ & \left.\log L\left(\boldsymbol{\theta} \mid \boldsymbol{a}_{1: T}, \boldsymbol{c}_{1: T}\right) \mid \hat{\boldsymbol{\theta}}^{(n-1)}\right\} \\
= & \sum_{i=1}^{S} \operatorname{Pr}\left\{s_{1}=i \mid \boldsymbol{a}_{1: T}, \boldsymbol{c}_{1: T}, \hat{\boldsymbol{\theta}}^{(n-1)}\right\} \\
& {\left[-\frac{1}{2}\left(\boldsymbol{c}_{1}-\boldsymbol{\mu}_{i}\right)^{\prime} \boldsymbol{V}\left(\boldsymbol{c}_{1}-\boldsymbol{\mu}_{i}\right)\right] } \\
+ & \sum_{t=2}^{T} \sum_{i=1}^{S} \sum_{j=1}^{S} \\
& \operatorname{Pr}\left\{s_{t-1}=i, s_{t}=j \mid \boldsymbol{a}_{1: T}, \boldsymbol{c}_{1: T}, \hat{\boldsymbol{\theta}}^{(n-1)}\right\} \\
& {\left[\log p_{i j}-\frac{1}{2}\left(\boldsymbol{c}_{t}-\boldsymbol{\mu}_{j}\right)^{\prime} \boldsymbol{V}\left(\boldsymbol{c}_{t}-\boldsymbol{\mu}_{j}\right)\right] } \\
+ & \sum_{t=1}^{T} \sum_{i=1}^{S} \operatorname{Pr}\left\{s_{t}=i \mid \boldsymbol{a}_{1: T}, \boldsymbol{c}_{1: T}, \hat{\boldsymbol{\theta}}^{(n-1)}\right\} \\
& {\left[\frac{1}{2} \mathrm{E}\left\{\boldsymbol{a}_{t} \mid s_{t}=i, \boldsymbol{\theta}\right\}^{\prime} \boldsymbol{\Omega}_{i}^{-1} \mathrm{E}\left\{\boldsymbol{a}_{t} \mid s_{t}=i, \boldsymbol{\theta}\right\}\right.} \\
& \left.-\log \sqrt{(2 \pi)^{K} \operatorname{det}\left(\boldsymbol{\Omega}_{i}\right)}\right]
\end{aligned}
$$

where $\boldsymbol{a}_{1: T}$ and $\boldsymbol{c}_{1: T}$ are the time series of $\boldsymbol{a}_{t}$ and $\boldsymbol{c}_{t}$ for time interval 1 to $T$, and $\mathrm{E}\left\{\boldsymbol{a}_{t} \mid s_{t}=i, \boldsymbol{\theta}\right\}$ is the expected value of $\boldsymbol{a}_{t}$ given $\boldsymbol{\theta}$ and that $s_{t}=i$ :

$$
\mathrm{E}\left\{\boldsymbol{a}_{t} \mid s_{t}=i, \boldsymbol{\theta}\right\}=\boldsymbol{\delta}_{i}+\operatorname{diag}\left(\boldsymbol{a}_{t-1}\right) \lambda_{i}+\boldsymbol{\Gamma}_{i} \boldsymbol{c}_{t}
$$

The maximization step finds the new parameter estimates $\hat{\boldsymbol{\theta}}^{(n)}$ by maximizing equation (A1) with respect to $\boldsymbol{\theta}$. The conditional state probability terms in equation (A1) are estimated by the Baum-Welch algorithm (Baum et al. 1970, Rabiner 1989).

To obtain $\hat{\boldsymbol{p}}_{i j}^{(n)}$, we maximize the right term of equation (A1) with respect to $p_{i j}$ using Lagrange multipliers to enforce the constraints $\sum_{j=1}^{S} p_{i j}=1$ for $i=1, \ldots, S$ :

$$
\begin{gathered}
\frac{\partial}{\partial p_{\mathrm{ij}}}\left[\mathrm{E}\left\{\log L\left(\boldsymbol{\theta} \mid \boldsymbol{a}_{1: T}, \boldsymbol{c}_{1: T}\right) \mid \hat{\boldsymbol{\theta}}^{(n-1)}\right\}\right. \\
\left.+\psi\left(1-\sum_{j=1}^{S} p_{i j}\right)\right]=0
\end{gathered}
$$

which becomes

$$
\sum_{t=2}^{T} \frac{\operatorname{Pr}\left\{s_{t-1}=i, s_{t}=j \mid \boldsymbol{a}_{1: T}, \boldsymbol{c}_{1: T}, \hat{\boldsymbol{\theta}}^{(n-1)}\right\}}{p_{i j}}-\psi=0
$$

Setting the constraint $\sum_{j=1}^{S} p_{i j}=1$, we find that

$$
\begin{gathered}
\psi=\sum_{j=1}^{S} \operatorname{Pr}\left\{s_{t-1}=i, s_{t}=j \mid \boldsymbol{a}_{1: T}, \boldsymbol{c}_{1: T}, \hat{\boldsymbol{\theta}}^{(n-1)}\right\}= \\
\operatorname{Pr}\left\{s_{t-1}=i \mid \boldsymbol{a}_{1: T}, \boldsymbol{c}_{1: T}, \hat{\boldsymbol{\theta}}^{(n-1)}\right\}
\end{gathered}
$$

The estimate of $p_{i j}$ is then

$\hat{p}_{i j}^{(n)}=\frac{\sum_{t=2}^{T} \operatorname{Pr}\left\{s_{t-1}=i, s_{t}=j \mid \boldsymbol{a}_{1: T}, \boldsymbol{c}_{1: T}, \hat{\boldsymbol{\theta}}^{(n-1)}\right\}}{\sum_{t=2}^{T} \operatorname{Pr}\left\{s_{t-1}=i \mid \boldsymbol{a}_{1: T}, \boldsymbol{c}_{1: T}, \hat{\boldsymbol{\theta}}^{(n-1)}\right\}}$

To compute $\hat{\boldsymbol{\mu}}_{j}^{(n)}$, we maximize the right term of equation (A1) with respect to $\boldsymbol{\mu}_{j}$ :

$$
\nabla_{\boldsymbol{\mu}} \mathrm{E}\left\{\log L\left(\boldsymbol{\theta} \mid \boldsymbol{a}_{1: T}, \boldsymbol{c}_{1: T}\right) \mid \hat{\boldsymbol{\theta}}^{(n-1)}\right\}=\boldsymbol{0}_{K}
$$

which becomes

$\sum_{t=1}^{M} \operatorname{Pr}\left\{s_{t}=j \mid \boldsymbol{a}_{1: T}, \boldsymbol{c}_{1: T}, \hat{\boldsymbol{\theta}}^{(n-1)}\right\}\left(\boldsymbol{c}_{t}-\boldsymbol{\mu}_{j}\right)=\boldsymbol{0}_{K}$

where $\boldsymbol{0}_{K}$ is a $K$-long vector of zeroes. The estimate of $\boldsymbol{\mu}_{j}$ is then 


$$
\hat{\boldsymbol{\mu}}_{j}^{(n)}=\frac{\sum_{t=1}^{T} \operatorname{Pr}\left\{s_{t}=j \mid \boldsymbol{a}_{1: T}, \boldsymbol{c}_{1: T}, \hat{\boldsymbol{\theta}}^{(n-1)}\right\} \boldsymbol{c}_{t}}{\sum_{t=1}^{T} \operatorname{Pr}\left\{s_{t}=j \mid \boldsymbol{a}_{1: T}, \boldsymbol{c}_{1: T}, \hat{\boldsymbol{\theta}}^{(n-1)}\right\}}
$$

To estimate the parameters of the multivariate ARX spells, we maximize the right term of equation (A1) with respect to $\boldsymbol{\delta}_{i}, \lambda_{i}, \boldsymbol{\Gamma}_{i}$ and $\boldsymbol{\Omega}_{i}$ :

$$
\begin{aligned}
& \nabla_{\boldsymbol{\delta}_{j}} \mathrm{E}\left\{\log L\left(\boldsymbol{\theta} \mid \boldsymbol{a}_{1: T}, \boldsymbol{c}_{1: T}\right) \mid \hat{\boldsymbol{\theta}}^{(n-1)}\right\}=\boldsymbol{0}_{K} \\
& \nabla_{\lambda_{j}} \mathrm{E}\left\{\log L\left(\boldsymbol{\theta} \mid \boldsymbol{a}_{1: T}, \boldsymbol{c}_{1: T}\right) \mid \hat{\boldsymbol{\theta}}^{(n-1)}\right\}=\boldsymbol{\boldsymbol { O }}_{K} \\
& \nabla_{\boldsymbol{\Gamma}_{j}} \mathrm{E}\left\{\log L\left(\boldsymbol{\theta} \mid \boldsymbol{a}_{1: T}, \boldsymbol{c}_{1: T}\right) \mid \hat{\boldsymbol{\theta}}^{(n-1)}\right\}=\boldsymbol{0}_{K \times N} \\
& \nabla_{\boldsymbol{\Omega}_{j}} \mathrm{E}\left\{\log L\left(\boldsymbol{\theta} \mid \boldsymbol{a}_{1: T}, \boldsymbol{c}_{1: T}\right) \mid \hat{\boldsymbol{\theta}}^{(n-1)}\right\}=\boldsymbol{0}_{K \times K}
\end{aligned}
$$

where $\boldsymbol{0}_{K \times N}$ is a $K \times N$ matrix of zeroes. Equations (A10), (A11) and (A12) constitute a linear system of $K(N+2)$ equations in $K(N+2)$ variables:

$$
\begin{gathered}
X_{i}=\sum_{t=1}^{T} \operatorname{Pr}\left\{s_{t}=i \mid \boldsymbol{a}_{1: T}, \boldsymbol{c}_{1: T}, \hat{\boldsymbol{\theta}}^{(n-1)}\right\} \\
{\left[\begin{array}{ccc}
\boldsymbol{I}_{K \times K} & \operatorname{diag}\left(\boldsymbol{a}_{t-1}\right) & \boldsymbol{C}_{t} \\
\operatorname{diag}\left(\boldsymbol{a}_{t-1}\right) & \operatorname{diag}\left(\boldsymbol{a}_{t-1}\right)^{2} & \operatorname{diag}\left(\boldsymbol{a}_{t-1}\right) \boldsymbol{C}_{t} \\
c_{t}(1) \boldsymbol{I}_{K \times K} & c_{t}(1) \operatorname{diag}\left(\boldsymbol{a}_{t-1}\right) & c_{t}(1) \boldsymbol{C}_{t} \\
\vdots & \vdots & \vdots \\
c_{t}(N) \boldsymbol{I}_{K \times K} & c_{t}(N) \operatorname{diag}\left(\boldsymbol{a}_{t-1}\right) & c_{t}(N) \boldsymbol{C}_{t}
\end{array}\right]} \\
\boldsymbol{b}_{i}=\sum_{t=1}^{T} \operatorname{Pr}\left\{s_{t}=i \mid \boldsymbol{a}_{1: T}, \boldsymbol{c}_{1: T}, \hat{\boldsymbol{\theta}}^{(n-1)}\right\} \\
{\left[\begin{array}{c}
\boldsymbol{a}_{t} \\
\operatorname{diag}\left(\boldsymbol{a}_{t-1}\right) \boldsymbol{a}_{t} \\
c_{t}(1) \boldsymbol{a}_{t} \\
\vdots \\
c_{t}(N) \boldsymbol{a}_{t}
\end{array}\right]}
\end{gathered}
$$

where $\boldsymbol{I}_{K \times K}$ is an identity matrix and $\boldsymbol{C}_{\mathrm{t}}$ is a $K \times K N$ auxiliary matrix:

$$
\begin{aligned}
& \sum_{t=1}^{T} \operatorname{Pr}\left\{s_{t}=i \mid \boldsymbol{a}_{1: T}, \boldsymbol{c}_{1: T}, \hat{\boldsymbol{\theta}}^{(n-1)}\right\}\left[\boldsymbol{\delta}_{i}+\operatorname{diag}\left(\boldsymbol{a}_{t-1}\right) \lambda_{i}+\boldsymbol{\Gamma}_{i} \boldsymbol{c}_{t}-\boldsymbol{a}_{t}\right]=\boldsymbol{0}_{K} \\
& \sum_{t=1}^{T} \operatorname{Pr}\left\{s_{t}=i \mid \boldsymbol{a}_{1: T}, \boldsymbol{c}_{1: T}, \hat{\boldsymbol{\theta}}^{(n-1)}\right\} \operatorname{diag}\left(\boldsymbol{a}_{t-1}\right)\left[\boldsymbol{\delta}_{i}+\operatorname{diag}\left(\boldsymbol{a}_{t-1}\right) \lambda_{i}+\boldsymbol{\Gamma}_{i} \boldsymbol{c}_{t}-\boldsymbol{a}_{t}\right]=\boldsymbol{0}_{K} \\
& \sum_{t=1}^{T} \operatorname{Pr}\left\{s_{t}=i \mid \boldsymbol{a}_{1: T}, \boldsymbol{c}_{1: T}, \hat{\boldsymbol{\theta}}^{(n-1)}\right\}\left[\boldsymbol{\delta}_{i}+\operatorname{diag}\left(\boldsymbol{a}_{t-1}\right) \lambda_{i}+\boldsymbol{\Gamma}_{i} \boldsymbol{c}_{t}-\boldsymbol{a}_{t}\right] \boldsymbol{c}^{\prime}{ }_{t}=\boldsymbol{0}_{K \times N}
\end{aligned}
$$

which can be written as

$$
\boldsymbol{X}_{i} \boldsymbol{u}_{i}=\boldsymbol{b}_{i}
$$

where

$$
\boldsymbol{u}_{i}=\left[\begin{array}{c}
\boldsymbol{\delta}_{i} \\
\lambda_{i} \\
\boldsymbol{\Gamma}_{i}(1,1) \\
\vdots \\
\boldsymbol{\Gamma}_{i}(1, N) \\
\vdots \\
\vdots \\
\boldsymbol{\Gamma}_{i}(K, 1) \\
\vdots \\
\boldsymbol{\Gamma}_{i}(K, N)
\end{array}\right]
$$

$$
\boldsymbol{C}_{t}=\left[\begin{array}{cccc}
\boldsymbol{c}_{\boldsymbol{t}}^{\prime} & & & \boldsymbol{0}_{1 \times N(K-1)} \\
\boldsymbol{0}_{1 \times N} & \boldsymbol{c}_{\boldsymbol{t}}^{\prime} & & \boldsymbol{0}_{1 \times N(K-2)} \\
\vdots & & \ddots & \vdots \\
\boldsymbol{0}_{1 \times N(K-1)} & & & \boldsymbol{c}_{\boldsymbol{t}}^{\prime}
\end{array}\right]
$$

The estimates of $\boldsymbol{\delta}_{\boldsymbol{i}}, \boldsymbol{\lambda}_{i}$ and $\boldsymbol{\Gamma}_{i}$ are obtained by solving the system in equation (A15):

$$
\boldsymbol{u}_{i}^{(n)}=\boldsymbol{X}_{i}^{-1} \boldsymbol{b}_{i}
$$

We can now compute the estimate of $\boldsymbol{\Omega}_{i}$. Noting that $\operatorname{det}\left(\boldsymbol{\Omega}_{i}^{-1}\right)=\operatorname{det}\left(\boldsymbol{\Omega}_{i}\right)^{-1}$ and $\nabla_{\boldsymbol{\Omega}_{i}^{-1}} \operatorname{det}\left(\boldsymbol{\Omega}_{i}^{-1}\right)=$ $\operatorname{det}\left(\boldsymbol{\Omega}_{i}^{-1}\right) \boldsymbol{\Omega}_{i}$, and substituting $\boldsymbol{\delta}_{\boldsymbol{i}}, \boldsymbol{\lambda}_{i}$ and $\boldsymbol{\Gamma}_{i}$ with the estimates $\hat{\boldsymbol{\delta}}_{i}^{(n)}, \hat{\lambda}_{i}^{(n)}$ and $\hat{\boldsymbol{\Gamma}}_{i}^{(n)}$, equation (A13) becomes 


$$
\begin{aligned}
& \sum_{t=1}^{T} \operatorname{Pr}\left\{s_{t}=i \mid \boldsymbol{a}_{1: T}, \boldsymbol{c}_{1: T}, \hat{\boldsymbol{\theta}}^{(n-1)}\right\} \\
& {\left[\frac{1}{2}\left(\boldsymbol{a}_{t}-\mathrm{E}\left\{\boldsymbol{a}_{t} \mid s_{t}=i, \hat{\boldsymbol{\theta}}^{(n)}\right\}\right)\right.} \\
&\left.\left(\boldsymbol{a}_{t}-\mathrm{E}\left\{\boldsymbol{a}_{t} \mid s_{t}=i, \hat{\boldsymbol{\theta}}^{(n)}\right\}\right)^{\prime}-\boldsymbol{\Omega}_{i}\right]=\boldsymbol{0}_{K \times K}
\end{aligned}
$$

The estimate of $\boldsymbol{\Omega}_{i}$ is then

$$
\boldsymbol{\Omega}_{i}^{(n)}=\frac{\sum_{t=1}^{T} \operatorname{Pr}\left\{s_{t}=i \mid \boldsymbol{a}_{1: T}, \boldsymbol{c}_{1: T}, \hat{\boldsymbol{\theta}}^{(n-1)}\right\}\left(\boldsymbol{a}_{t}-\mathrm{E}\left\{\boldsymbol{a}_{\boldsymbol{t}} \mid s_{t}=i, \hat{\boldsymbol{\theta}}^{(n)}\right\}\right)\left(\boldsymbol{a}_{t}-\mathrm{E}\left\{\boldsymbol{a}_{t} \mid s_{t}=i, \hat{\boldsymbol{\theta}}^{(n)}\right\}\right)^{\prime}}{\sum_{t=1}^{T} \operatorname{Pr}\left\{s_{t}=i \mid \boldsymbol{a}_{1: T}, \boldsymbol{c}_{1: T}, \hat{\boldsymbol{\theta}}^{(n-1)}\right\}}
$$

\section{APPENDIX B}

Dynamic programming benchmark solution

Given a discrete set of feasible reservoir water level pairs and assuming perfect knowledge of inflow, dynamic programming (DP) is used to find the monthly time series of level pairs that minimizes expected RMSHD while meeting the downstream water demands.

Let $X$ be the discrete set on which the reservoir water level pairs take values at the end of monthly time intervals, i.e. $\boldsymbol{h}_{t} \in X$. Given the inflow values $\boldsymbol{q}_{t}=\left[q_{t}^{e}, q_{t}^{a}\right]$ and the assumptions made in Section 5.1 , turbine releases and generated power during time interval $t$ are functions of $\boldsymbol{h}_{t-1}$ and $\boldsymbol{h}_{t}$ :

$$
\begin{aligned}
& \boldsymbol{r}_{t}=\boldsymbol{r}\left(\boldsymbol{h}_{t-1}, \boldsymbol{h}_{t} \mid \boldsymbol{q}_{t}\right) \\
& g_{t}=g\left(\boldsymbol{h}_{t-1}, \boldsymbol{h}_{t} \mid \boldsymbol{q}_{t}\right)
\end{aligned}
$$

To find a solution that satisfies the downstream water demands, the square hydropower deficit for $t$ is defined as:

$$
y_{t}\left(\boldsymbol{h}_{t-1}, \boldsymbol{h}_{t} \mid \boldsymbol{q}_{t}\right)= \begin{cases}\left(G-g_{t}\right)^{2} & \text { if } r_{t}^{e} \geq W^{e} \wedge r_{t}^{a} \geq W^{a} \\ \infty & \text { otherwise }\end{cases}
$$

Then, the expected RMSHD from time interval $T_{T 1}$ to $T_{2}$ is:

$$
Y\left(\boldsymbol{h}_{T_{1}: T_{2}} \mid \boldsymbol{q}_{T_{1}: T_{2}}\right)=\sqrt{\frac{1}{T_{2}-T_{1}} \sum_{t=T_{1}}^{T_{2}-1} y_{t}\left(\boldsymbol{h}_{t}, \boldsymbol{h}_{t+1} \mid \boldsymbol{q}_{t+1}\right)}
$$

where $\boldsymbol{h}_{T_{1}: T_{2}}$ is the time series of water levels from time interval $T_{1}$ to $T_{2}$.

The time series of reservoir water levels $\boldsymbol{h}^{*}{ }_{T_{1}: T_{2}}$ that minimizes $Y$ is found by solving the following minimization problem via DP:

$$
\boldsymbol{h}_{\boldsymbol{T}_{1}: \boldsymbol{T}_{2}}^{*}=\underset{\boldsymbol{h}_{T_{1}: T_{2}}}{\arg \min }\left\{Y\left(\boldsymbol{h}_{T_{1}: T_{2}} \mid \boldsymbol{q}_{T_{1}: T_{2}}\right)\right\}
$$

